\title{
LONG-TERM CLINICOPATHOLOGICAL, COSMETIC AND QUALITY OF LIFE COMPARISON OF ONCOPLASTIC AND CONVENTIONAL BREAST-CONSERVING SURGERY TOWARDS THE STANDARDIZATION OF ONCOPLASTIC TECHNIQUES
}

\author{
Ph.D. Thesis
}

Bertalan Péter Kelemen M.D.

Szeged

2020 


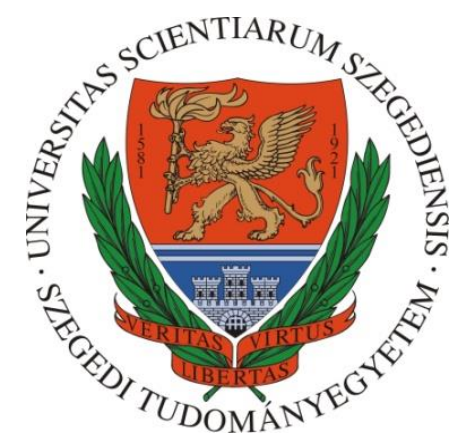

Ph.D. Thesis

Long-term clinicopathological, cosmetic and quality of life comparison of oncoplastic and conventional breast-conserving surgery towards the standardization of oncoplastic techniques

Bertalan Péter Kelemen, M.D.

Supervisor:

habil. Zoltán Mátrai M.D., Ph.D.

Department of Breast and Sarcoma Surgery

National Institute of Oncology

University of Szeged, Faculty of Medicine

Doctoral School of Interdisciplinary Medicine

Szeged

2020 


\section{LIST OF FULL PAPERS THAT SERVED AS THE BASIS OF THE PH.D. THESIS}

I. Kelemen P, Pukancsik D, Újhelyi M, Sávolt Á, Kovács E, Ivády G, Kenessey I, Kovács T, Stamatiou A, Smanykó V, Mátrai Z.

Comparison of clinicopathologic, cosmetic and quality of life outcomes in 700 oncoplastic and conventional breast-conserving surgery cases: A single-centre retrospective study. Eur J Surg Oncol. 2019 Feb; 45 (2):118-124. doi: 10.1016/j.ejso.2018.09.006. Epub 2018 Oct 16.

IF : 3.379*

II. Kelemen P, Pukancsik D, Újhelyi M, Kovács E, Stamatiou A, Ivády G, Kenessey I, Kovács T, Smanykó V, Rubovszky G, Mátrai Z.

Evaluation of the central pedicled, modified Wise-pattern technique as a standard level II oncoplastic breast-conserving surgery: A retrospective clinicopathological study of 190 breast cancer patients.

Breast J. 2019 Sep; 25(5):922-926. doi: 10.1111/tbj.13371. Epub 2019 Jun 4. IF $: 2.433 *$

III. Kelemen P, Ujhelyi M, Pukancsik D, Sávolt A., Kovács E., Zaka Z., Sándor Zs, Mátrai Z Evaluation of the modified Regnault "B" technique as a standard Level II oncoplastic breastconserving surgery. A retrospective clinico-pathological and aesthetic study of 215 breast cancer patients.

Orv Hetil. 2020 marc;161(24): 1002-1011. doi: 10.1556/650.2020.31738 PMID: 32469841 IF $: 0.564 *$ 


\section{OTHER PUBLICATIONS RELATED TO THE THEME OF THE THESIS}

I. Pukancsik D., Kelemen P., Sávolt Á., Újhelyi M., Kovács E., Zaka Z., Kásler M., Mátrai Z.

Evaluation of clinicopathological findings and cosmetic outcome of 100 immediate postmastectomy breast reconstruction cases

Orv Hetil. 2016 Nov;157(46):1830-1838

IF : 0.349

II. Pukancsik D., Mátrai T., Kelemen P., Sávolt Á., Újhelyi M., Mátrai Z.

The modern surgery of breast cancer

Focus Medicinae 2016. XVIII. évf. 4.

III. Újhelyi M., Pukancsik D., Kelemen P., Kovács E., Kenessey I., Udvarhelyi N., Bak M., Kovács T., Mátrai Z.

Does breast screening offer a survival benefit? A retrospective comparative study of oncological outcomes of screen-detected and symptomatic early stage breast cancer cases. Eur J Surg Oncol. 2016 Dec;42(12):1814-1820.

IF $: 3.522$

IV. Újhelyi M., Pukancsik D., Kelemen P., Sávolt Á., Gődény M., Kovács E., Udvarhelyi N., Bak M., Polgár C., Rubovszky G., Kásler M., Mátrai Z.

Breast cancer care quality analysis of the National Institute of Oncology in Hungary according to the requirements of European Society of Breast Cancer Specialists (EUSOMA) Orv Hetil. 2016 Oct;157(42):1674-1682.

IF $: 0.349$

V. Pukancsik D, Kelemen P, Gulyás G, Újhelyi M, Kovács E, Éles K, Mészáros N, Kenessey I, Pálházi P, Kovács T, Kásler M, Mátrai Z

Clinical experiences with the use of ULTRAPRO ${ }^{\circledR}$ mesh in single-stage direct-to-implant immediate postmastectomy breast reconstruction in 102 patients: A retrospective cohort study.

Eur J Surg Oncol. 2017 Feb 6. pii: S0748-7983(17)30332-3.

IF $: 3.688$ 
VI. Pukancsik D, Kelemen P, Újhelyi M, Kovács E, Udvarhelyi N, Mészáros N, Kenessey I, Kovács T, Kásler M, Mátrai Z

Objective decision making between conventional and oncoplastic breast-conserving surgery or mastectomy: An aesthetic and functional prospective cohort study.

Eur J Surg Oncol. 2017 Feb;43(2):303-310.

IF $: 3.522$

VII. Újhelyi M, Pukancsik D, Kelemen P, Kovács E, Kenessey I, Bak M, Kásler M, Kovács T, Mátrai Z.

Barriers to Organized Mammography Screening Programs in Hungary: A Questionnairebased Study of 3,313 Women.

Anticancer Res. 2018 Mar;38(3):1727-1734.

IF $: 1.935$

VIII. Dorogi B, Bukovszky B, Mátrai T, Sávolt Á, Polgár C, Kelemen P, Kovács T, RényiVámos F, Ivády G, Kovács E, Téglás M, Kásler M, Mátrai Z.

Mapping of the functional anatomy of lymphatic drainage to the axilla in early breast cancer: A cohort study of 933 cases.

Eur J Surg Oncol. 2019 Feb;45(2):103-109. doi: 10.1016/j.ejso.2018.08.030. Epub 2018 Oct 7.

IF $: 3.379 *$

IX. Mátrai Z, Újhelyi M, Kovács T, Kelemen P, Sávolt Á, Kovács E, Éles K, Mészáros N, Kenessey I, Stamatiou A, Pukancsik D.

Evaluation of a Retroglandular Oncoplastic Technique as a Standard Level I Oncoplastic Breast-Conserving Surgery: A Retrospective Clinicopathologic Study of 102 Patients With Breast Cancer.

Clin Breast Cancer. 2019 Jun;19(3):e459-e467. doi: 10.1016/j.clbc.2019.02.005. Epub 2019 Feb 20

IF $: 2.762 *$ 
X. Sávolt Á, Cserni G, Lázár G, Maráz R, Kelemen P, Kovács E, Győrffy B, Udvarhelyi N, Vörös A, Ormándi K, Mátrai Z.

Sentinel lymph node biopsy following previous axillary surgery in recurrent breast cancer.

Eur J Surg Oncol. 2019 Oct;45(10):1835-1838. doi: 10.1016/j.ejso.2019.05.016. Epub 2019 May 16.

IF $: 3.379 *$

$\sum 22.885^{*}$

*expected impact factor value 


\section{CONTENTS}

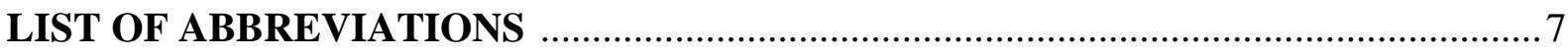

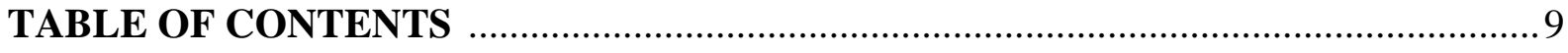

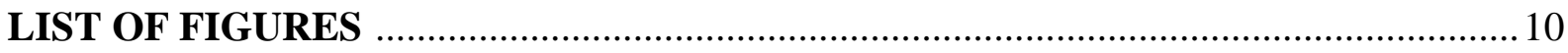

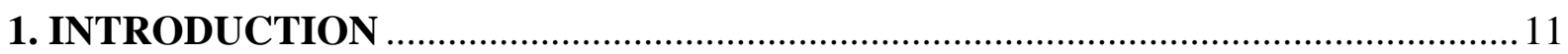

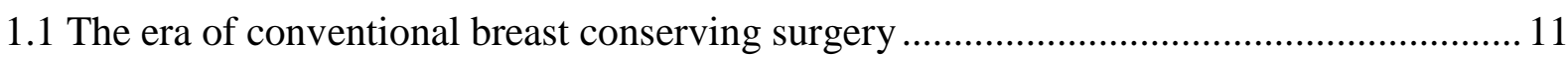

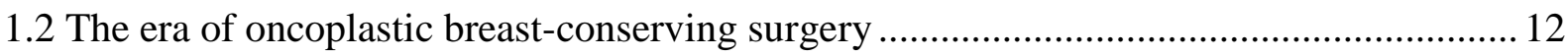

1.3 Techniques and standardization of oncoplastic breast-conserving surgery ...................... 12

1.4 Oncological safety of oncoplastic breast-conserving surgery ...................................... 14

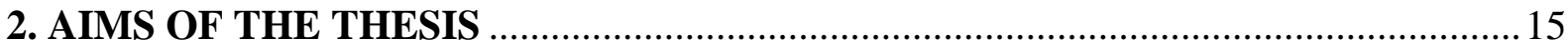

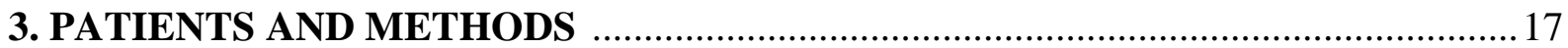

3.1 Long-term comparison of clinicopathological, cosmetic and quality of life outcomes in 700 oncoplastic and conventional breast-conserving surgery cases

3.2 Evaluation of the central pedicled, modified Wise-pattern technique as a standard level II oncoplastic breast-conserving surgery: A retrospective clinicopathological study of 190 breast cancer patients

3.3 Evaluation of the modified Regnault "B" technique as a standard Level II oncoplastic breast-conserving surgery. A retrospective clinico-pathological and aesthetic study of 215 breast cancer patients

\section{RESULTS} 36

4.1 Long-term comparison of clinicopathological, cosmetic and quality of life outcomes in 700 oncoplastic and conventional breast-conserving surgery cases

4.2 Evaluation of the central pedicled, modified Wise-pattern technique as a standard level II oncoplastic breast-conserving surgery: A retrospective clinicopathological study of 190 breast cancer patients 
4.3 Evaluation of the modified Regnault " $\mathrm{B}$ " technique as a standard Level II oncoplastic breast-conserving surgery. A retrospective clinico-pathological and aesthetic study of 215 breast cancer patients

5.1 Comparing the clinicopathological, cosmetic and quality of life outcomes of oncoplastic breast conserving surgery to conventional one. - based on the results of study 4.1.

5.2 Assessing the clinipathological, cosmetic and quality of life outcomes of the central pedicled, modified Wise-pattern oncoplastic technique - based on the results of study 4.2. .. 53

5.3 Assessing the clinipathological, cosmetic and quality of life outcomes of the modified Regnault "B" oncoplastic technique - based on the results of study 4.3. 


\section{LIST OF ABBREVIATIONS}

A+TAX: doxorubicin and paclitaxel

AC: doxorubicin and cyclophosphamide

ADM-TXT: doxorubicin and docetaxel

ALND: Axillary lymph node dissection

BCS: breast-conserving surgery

BCTOS: Breast Cancer Treatment Outcome Scale

BCCT.core: Breast Cancer Conservative software

Treatment-cosmetic results

BMI: body mass index

BRCA: breast cancer gene

CBCS: conventional breast-conserving surgery

$\mathrm{CR}$ : complete regression

DCIS: ductal carcinoma in situ

DFS: disease free survival

EBSQ: European Board of Surgical Qualification

EC: epirubicin and cyclophosphamide

EIC: extensive intraductal component

EORTC: European Organisation for Research and Treatment of Cancer

EPI-TXT: epirubicin and docetaxel

ER: oestrogen receptor

ESMO: European Society of Medical Oncology

ESSO: European Society of Surgical Oncology

FISH: fluorescence in situ hybridization

HER2: human epidermal growth factor receptor 2

IMF: inframammary fold

LR: local recurrence

LRR: locoregional recurrence

LHRH: Luteinizing hormone-releasing hormone

NAC: nipple-areola complex

NIO: National Institute of Oncology

NSABP: National Surgical Adjuvant Breast and Bowel Project

NST: no special type 
OBCS: oncoplastic breast-conserving surgery

OS: overall survival

OPS: oncoplastic surgery

PST: primary systemic therapy

PR: progesterone receptor

QLQ: quality of life

$\mathrm{RT}$ : radiotherapy

SLNB: sentinel lymph node biopsy

ST: stage

TN: triple-negative

TM: therapeutic mammoplasty

TNM: Tumour, Node, Metastatis Classification

UEMS: European Union of Medical Specialists

US: ultrasound

WBI: whole breast irradiation 


\section{TABLE OF CONTENTS}

Table 1. Patients' characteristics

Table 2. Comparison of the tumour characteristics of the oncoplastic and the conventional breast-conserving surgery groups

Table 3. Techniques of the oncoplastic breast-conserving sugery procedures

Table 4. Comparison of the complication rate in the oncoplastic and the conventional breastconserving surgery groups

Table 5. Summarizing the cup size, the affected quadrant and side of the breast

Table 6. Tumour characteristics

Table 7. Summarizing the complications regarding both on the therapeutic and on the nontherapeutic side

Table 8. Patient's characteristics and clinicopathological parameters

Table 9. Results of the BCCT.core and the BREAST-Q validated quality of life questionnaire 


\section{LIST OF FIGURES}

Figure 1. Illustration of the various volume displacement oncoplastic techniques in different subregions of the breast based on tumour location

Figure 2. Illustrating the three investigated volume displacement OBCS techniques

Figure 3. Illustrating the surgical steps of the central pedicled, modified Wise-pattern oncoplastic breast-conserving surgery technique

Figure 4. Illustrating the surgical steps of the modified Regnault " $\mathrm{B}$ " oncoplastic breastconserving surgery technique

Figure 5. Overall and disease free survival rate of oncoplastic and the conventional breastconserving surgery groups 


\section{INTRODUCTION}

Currently, the breast cancer is the most common malignant disease in women with a gradually increasing incidence and a relatively decreasing mortality rate of $11 \%$. [1,2] The Hungarian National Cancer Registry recorded 8520 new cases of breast cancer in women, with 2123 deaths in 2017. [3,4]

\subsection{The era of conventional breast conserving surgery}

Based on the well known prospective randomized studies of Umberto Veronesi (Milan-I) and Bernard Fisher (NSABP-04) in oncological breast surgery in the last four decades, breast conservation therapy (BCS) has become dominant in the surgical treatment of early stage breast cancers, which is proven to provide survival rates equal to mastectomy if combined with adjuvant whole breast irradiation (WBI) and microscopically negative surgical margin. [5-9]

In practice, the obvious benefits of conventional breast cancer surgery (CBCS) are overshadowed by the fact that in $5 \%$ to $30 \%$ of the cases, due to microscopically positive surgical margins, a completional surgery (guided reexcision or mastectomy), and in most cases, a 3-5-week-long, logistically demanding radiotherapy (RT) is needed, along with impaired cosmetic results or even a distorted breast in $30 \%$ of surgical cases. [10-13]

According to an earlier prospective cohort study performed by our working group, the reason for the latter is that the CBCS with adjuvant WBI could cause significant, intolerable cosmetic results for the patients with the loss of $10 \%$ total breast volume in the inner quadrants and $15 \%$ to $20 \%$ in the outer quadrants of the breast when compared to total breast volume. [14] In addition to volume loss, CBCS leaves the tumour bed as an open cavity, thus in the early postoperative period after the absorption of the seroma, the adjacent parenchyma and skin shrinks and is drawn in and adheres to the pectoral muscle or its fascia. This process is reinforced by the fact that due to WBI, the structure, elasticity and microcirculation of the complete residual parenchyma and skin are irreversibly altered, resulting in up to $10 \%$ to $20 \%$ shrinkage of the breast. As a result of the above undesired practically secondary wound healing process after CBCS, a characteristic deformity of the breast can occur usually with a curved scar directly above the tumour, with a decreased volume relative to the contralateral breast and the nipple is pulled away from the axis of the breast mound towards the affected breast quadrant. A further difficulty is that breast reconstruction following BCS usually necessitates more complex reconstructive techniques resulting in poorer cosmetic outcomes 
than delayed postmastectomy breast reconstructions, which respect the aesthetic units of the breast. $[15,16]$

\subsection{The era of oncoplastic breast-conserving surgery}

To overcome the above listed disadvantages of CBCS, sophisticated breast conserving surgeries have been developed with the adaptation of plastic surgical mammoplasty techniques over the last decade, which was named Oncoplastic Surgery (OPS) by Werner Audretsch. [17] The OPS includes the oncoplastic breast-conserving surgery (OBCS), correction of the defects of partial mastectomy based on the principles of reconstructive plastic surgery, contralateral breast symmetrization surgeries and immediate breast reconstruction (IBR) after mastectomy in wider sense. [18-20]

These OBCS are, in fact, breast volume reducing mastopexies or modifications thereof that are based on the knowledge of the anatomy of the breast, especially the blood supply (e.g., Würinger septum), and the structural and aesthetic subunits (e.g., inframammary fold (IMF), nipple-areola complex (NAC)). [18-20]

The basis of OBCS is that after radical removal of the tumour, the resulting cavity wound is filled by the mobilisation and transposition of the surrounding tissues (volume displacement) utilising breast ptosis, narrowing the overall base diameter, or footprint, and repositioning the NAC. Alternative to volume displacement is the volume replacement, including the use of local or distant autologous flaps, silicone implants or even autologous fat transfer. These OBCS techniques extend the options for BCS [21], able to improve aesthetic outcomes, provide higher patient satisfaction and result in better control of tumour margins. After OBCS, irradiation causes the scars left behind to become almost invisible, while in the absence of a cavity wound no adhesion occurs. [18-20]

\subsection{Techniques and standardization of OBCS}

According to Clough's recommendation OBCS can be classified as their technical complexity or volume to be replaced ( $<20 \%$ / 20\% to 50\%) (Level I. and II. OBCS). [22,23] Furthermore, the oncoplastic techniques can be related to volume displacement or replacement procedures. Among the procedures available, local flaps, latissimus dorsi myocutaneous flap and reduction mammaplasty/masthopexy techniques are the most commonly used based on the substructural, vascular supply of the breast. (Figure 1.) 


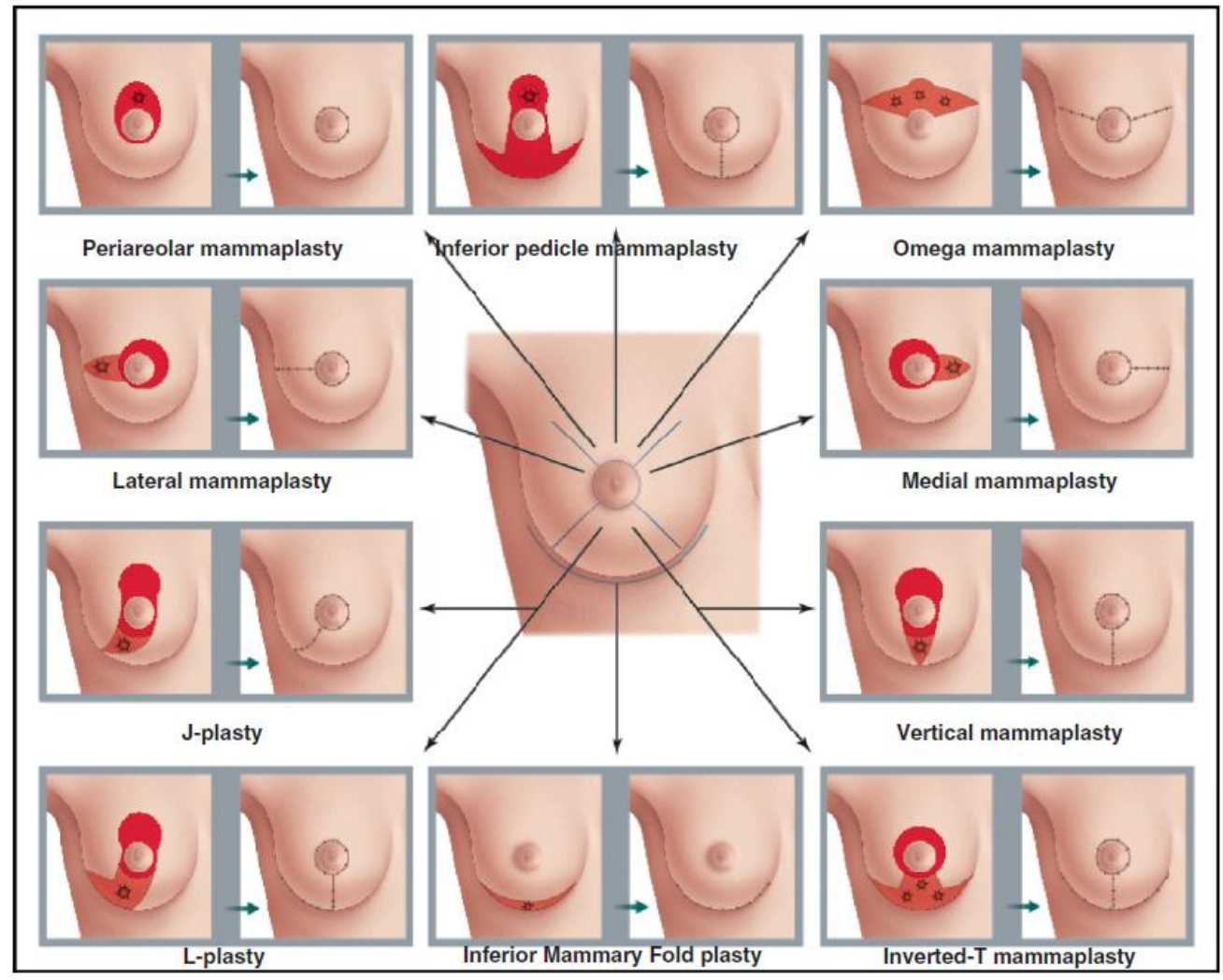

Figure 1. Illustration of the various "volume displacement" OPS techniques in different subregions of the breast based on tumour location [24]

The first OBCS techniques were described more than two decades ago. Since then, several OBCS techniques have been developed based on the size and shape of the breast as well as the size and location of the tumour. [25] Even though various detailed classification systems and algorithms have been suggested for use in clinical practice, they achieved neither standardization, nor acceptance on an international level. [18-20] [26] The lack of standardization of OBCS nomenclature, indication, and outcome assessment challenges the interpretation and comparison of an increasing body of observational evidence. Therefore, standardization of OBCS is necessary for structured education and training, and to plan welldesigned, prospective multicenter studies. [26,27]

According to the first international consensus conference on standardization of OBCS held in Basel 2017, the Clough bi-level classification was recommended for standard use in clinical practice for indicating, planning and performing OBCS, and the Hoffmann classification for surgical reports and billing purposes. [26] Mastopexy and reduction mammoplasty were the only two recognized OBCS procedure categories supported by a 
majority of the panel. Finally, the experts unanimously supported the statement that every OBCS procedure should be tailored to each individual patient. [26]

In general it can be stated that, currently there is still little standardization of OBCS. Further long-term studies needed to provide the OBCS techniques' reproducibility, utility, low interference with the oncologic treatment and higher satisfaction of breast cancer patients.

\subsection{Oncological safety of OBCS}

According to the first international consensus conference on standardization of OBCS the panelists stated that OBCS increases the risk of complications compared to CBCS. [26] This statement is supported by a recent review of 11 prospective studies including 998 patients with 7 studies reporting on complications. [28] Even though complication rates varied widely among studies, an early complication rate of $20 \%$ was commonly described, consisting mostly of delayed wound healing, partial skin necrosis, infection, hematoma, and seroma. Accordingly, a 3- to 8-fold increase in the risk of morbidity has been previously described. [29] Despite the potential impact of complications on the time to adjuvant therapy, virtually all panel members agreed that OBCS does not increase the risk of local recurrence (LR) compared to CBCS. In fact, even though there are no randomized controlled trials, there is an increasingly large body of observational evidence that consistently indicates that OBCS is oncologically safe, even though the length of follow-up is still limited. [30,31]

A recent systematic review of oncological outcomes after OBCS showed high rates of overall (95\%) and disease-free survival (90\%), as well as low rates of LR (3.2\%), positive margins (10.8\%) and re-excisions (6\%) at a mean follow-up of 4.2 years. [31] Concordantly, the largest single-center series published to date revealed no differences in overall and recurrence-free survival between the OBCS and CBCS groups at a median follow-up of 3.4 years. [30]

It is essential to know that high level evidence to support the oncological safety and improved aesthetic outcome of OBCS are still lacking, due to most of the current publications' retrospective, multicentric nature using non-standardized OBCS techniques with low number of enrolled patients and short follow-up time. Furthermore, - due to its complexity, - limited data is available of studies that directly compare OBCS and CBCS procedures facilitating the standardization of OBCS techniques. [26] 


\section{AIMS OF THE THESIS}

2.1 According to the first hypothesis, the locally standardized (therapeutic mammaplasty, dermoglandular rotation and periareolar) OBCS techniques in line with the CBCS: a. can provide the adequate oncological safety with low complication rate b. can provide the radical tumour resection, thus maintaining the local tumour control c. do not cause delay in initiation of adjuvant therapies

2.2 According to the second hypothesis, the OBCS techniques can provide higher quality of life and aesthetic outcomes with improved satisfaction of the breast cancer patients compared to $\mathrm{CBCS}$.

Revealing the above mentioned hypothesises, the main purpose is to gain wider acceptance of the OBCS techniques.

2.3 According to the third hypothesis, our newly described, modified Wise-pattern OBCS technique:

a. is oncologically safe procedure with low complication rate

b. can provide the radical tumour resection, thus maintaining the adequate surgical margin, and local tumour control

c. can provide improved quality of life and aesthetic outcomes resulting in high patient's satisfaction

Revealing the above mentioned hypothesis, the main purpose is the wider acceptance of the modified Wise-pattern OBCS, thus become a standard oncoplastic technique in any quadrant of the breast.

2.4 According to the fourth hypothesis, our newly described modified Regnault "B" OBCS technique:

a. is oncologically safe procedure with low complication rate

b. can provide the radical tumour resection, thus maintaining the adequate surgical margin, and local tumour control 
c. can provide improved quality of life and aesthetic outcomes resulting in high patient's satisfaction

Revealing the above mentioned hypothesis, the main purpose is the wider acceptance of the modified Regnault "B" OBCS, thus become a standard oncoplastic technique of the tumours located in the upper-outer quadrant as the most common location of the breast cancer. 


\section{PATIENTS AND METHODS}

3.1 Long-term comparison of clinicopathologic, cosmetic and quality of life outcomes in 700 oncoplastic and conventional breast-conserving surgery cases

A single-centre retrospective comparative study was performed between January 2010 and January 2017 at the National Institute of Oncology (NIO) in Budapest, Hungary. The study was approved by the institutional research ethics committee and involved 756 patients with stage 0 -III breast cancer.

In the investigated period, 378 patients underwent OBCS procedures (the OBCS group). As a control group, 378 patients treated with CBCS (the CBCS group) were randomly selected during the same period.

All the preoperative drawings and operations were performed by two qualified (European Board of Surgical Qualification, (EBSQ)) breast surgeons according to the decisions made by the multidisciplinary team.

In the retrospective processing, the exclusion criteria were as follows: oncologic follow-up of the patients was performed at another institute, the patients did not participate in the evaluation of the cosmetic and quality of life outcome measurements, the patient had a history of BCS and/or radiation therapy (RT), or the patient received immediate contralateral breast symmetrisation with therapeutic surgery.

In cases with breasts that were of moderate or large volume (cup size $\mathrm{B} / \mathrm{C}$ and greater) or ptotic (Regnault classification type II-III), a therapeutic mammaplasty (central pedicled or modified Wise-pattern, superior, or inferior pedicled Wise-pattern) OBCS was performed. In cases with medium or smaller sized (bra cup size B/C) or slightly ptotic breasts (Regnault classification Type I-II, pseudoptosis, parenchymal maldistribution) a dermoglandular rotation (medial, lateral mammoplasty) or periareolar (bra cup size A and greater, Regnault classification normal or Type I) (round block, omega) OBCS was performed. (Figure 2.a-i) 
Figure 2. Illustrating the three investigated volume displacement OBCS techniques
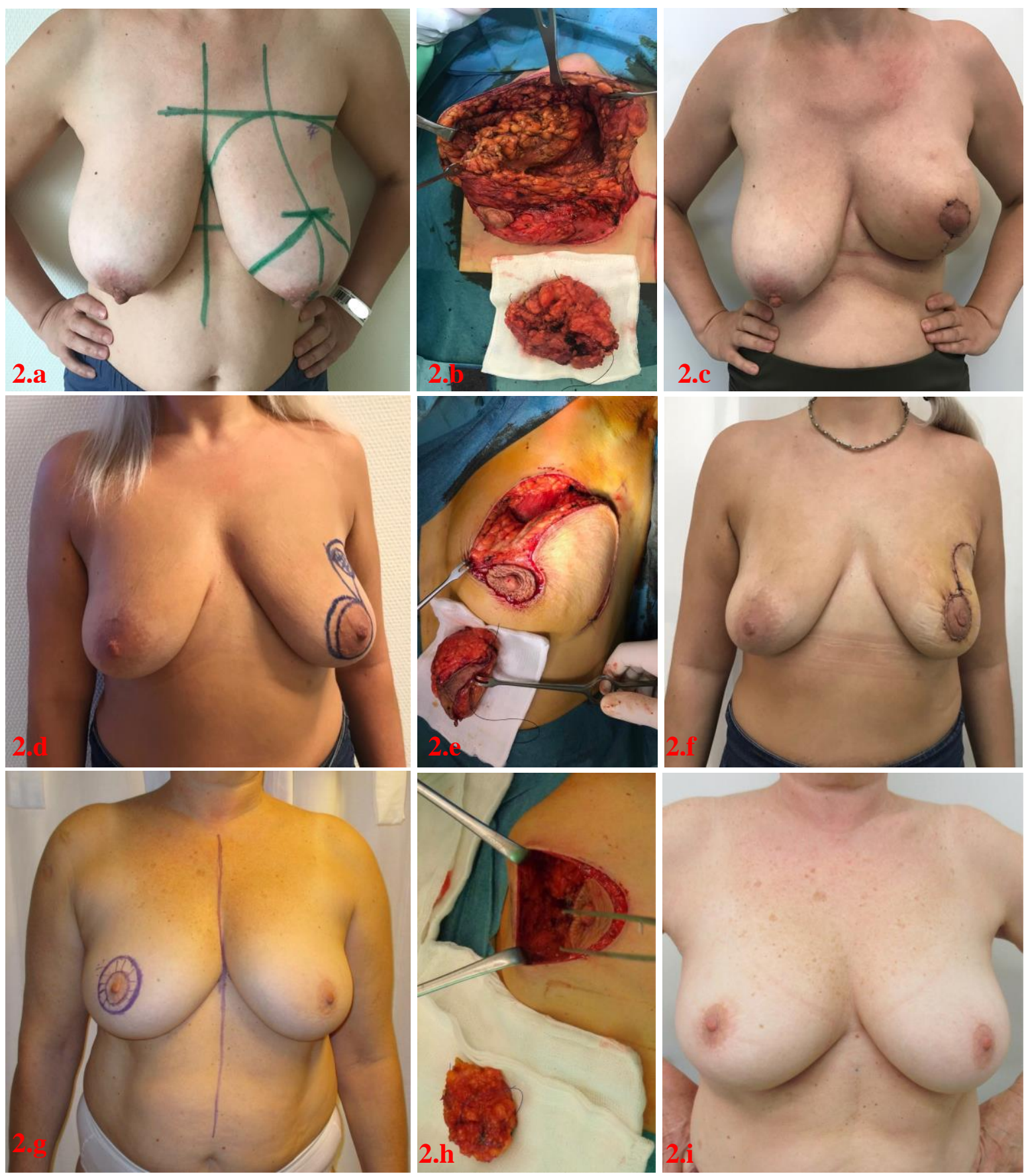

Figure 2.a-c.: Pre-, intra- and postoperative photos illustrating a left-sided oncoplastic therapeutic mammaplasty (inferior pedicle Wise-pattern) due to a cT2NOMO, luminal-A, invasive ductal carcinoma 
Figure 2.d-f.: Pre-, intra- and postoperative photos illustrating a left-sided (lateral) dermoglandular rotation oncoplastic surgery due to a cT2NOMO, luminal-A, invasive ductal carcinoma

Figure 2.g-i.: Pre-, intra- and postoperative photos illustrating a right-sided periareolar (round block) oncoplastic surgery due to a cT1cNOMO, luminal-B, invasive ductal carcinoma

Considering Clough's recommendations, all three aforementioned volume displacement OBCS techniques allowed level I or level II excision if it was necessary. [22]

The diagnosis of breast cancer, additional staging examinations and the follow-up of the patients were performed according to the institutional protocol based on that of the European Society of Medical Oncology (ESMO). [32]

At the time of the study, a minimum of a 1-mm tumour-free resection margin was considered a microscopically intact surgical margin (for invasive and in situ cancers as well), with the exception of the posterior and anterior margins if the surgery was performed with the maximum allowed radicality. After January 2015, the minimum surgical margin for invasive tumours was modified to "no cell on the inked surface", but the 1-mm safely margin remained unmodified for ductal carcinoma in situ (DCIS). [32]

The removal of non-palpable tumours was performed with radioguided occult lesion localization (ROLL) supplemented by intraoperative specimen mammography examination.

Intraoperative frozen section procedures were not applied routinely in cases of palpable tumours. In cases of sentinel lymph node biopsy (SLNB), intraoperative imprint cytology was applied.

Level I-III axillary lymph node dissection (ALND) was performed for patients with metastatic SLN on imprint cytology and for patients with unidentified SLN and clinically node positive cases. After the first of January 2015, ALND was omitted for limited axillary metastases according to the study criteria of ACOSOG Z0011 [33] and OTOASOR [34]. In selected cases, patients with metastatic axillary SLN were treated with axillary and supraclavicular RT.

All the analysed cases underwent whole-breast RT, with an overall dose of 50/2 or 40.05/2.67 Gy (external beam, 6-MV photon irradiation) and additional tumour bed boost irradiation (16/2 or 10/2.5 Gy) and/or axilla and supraclavicular irradiation if it was necessary.

Antibiotics for prophylaxis were not administered routinely during the surgeries. 
The database included each patient's age, body mass index (BMI), smoking habits, diabetic comorbidity, cup size, surgical technique (wide excision or quadrantectomy), type of OBCS techniques, type of axillary surgery, specimen weight, rate and type of completion surgery and operation time. The database also included the clinical and pathological TNM stage ( $7^{\text {th }}$ Edition) [35], histological type of the tumour, hormone receptor status, HER-2 receptor status, Grade, Ki-67 value, molecular subtype and nature of the microscopical surgical margin. Furthermore, the timing of the initiation of the adjuvant treatment in relation to the time of surgery, the types of adjuvant treatments used, the follow-up time from the time of the surgery, and the oncologic status of the patient were assessed.

Postoperative complications were divided into two categories. Minor complications included infection treated with antibiotics, haematoma, seroma, and partial skin/NAC necrosis that healed spontaneously. Complications requiring surgical intervention were classified as major complications and included haematoma, chronic infection and seroma (lasting for more than 2 weeks following the removal of the surgical drain), fat necrosis, and partial skin/NAC necrosis.

To assess the aesthetic results, a 5-point Likert scale (score: 1, strongly disagree; 2, disagree; 3 , undecided; 4 , agree; 5 , strongly agree) was used to judge the statement, "this case has an excellent aesthetic outcome". The evaluation was performed by a committee of 3 breast surgeons who gave a single score for each case at the first postoperative year.

The European Organisation for Research and Treatment of Cancer- Quality of Life Questionnaire (EORTC-QLQ) was applied to measure the quality of life of breast cancer patients at the first postoperative year. Selected scales were used in the QLQ-C30 and the QLQ-BR23 questionnaires such as the social functioning, emotional functioning and body image. Potential scores ranged from 0 to 100 , with a higher score indicating a higher prevalence. [36]

The collected data were analysed using Statistica 12.0 software. To compare the data between the OBCS and CBCS groups, the following statistical methods were used: in cases of categorical variables, Chi-square tests or Fisher's exact tests were used, while data showing non-normal distributions were analysed by Mann-Whitney U tests. Survival intervals were analysed using the Kaplan-Meier method and log-rank statistics. Statistical significance was determined when $\mathrm{p}$ values were $<0.05$. 
3.2 Evaluation of the central pedicled, modified Wise-pattern technique as a standard level II oncoplastic breast-conserving surgery: A retrospective clinicopathological study of 190 breast cancer patients

A single-institution, retrospective cohort study was performed between February 2011 and January 2017 using a prospective database at the NIO, Budapest, Hungary. The study was approved by the institutional research ethics committee and included 207 stage 0-III breast cancer patients.

Patients underwent therapeutic modified Wise-pattern OBCS with immediate or delayed contralateral symmetrization. The symmetrization was performed in the second stage if multifocality of the malignancy emerged, the extension of the tumour was indefinite, or comorbidities (e.g., diabetes mellitus) or active smoking existed.

According to the results of the final histological findings, the delayed symmetrization was performed between the $6^{\text {th }}$ postoperative month and the first postoperative year.

In the retrospective analysis, the exclusion criteria were as follows: oncologic followup of the patients was performed in another institution, patients did not participate in cosmetic outcome measurements, patients had a history of breast-conserving surgery and/or RT, genetic testing verified the BRCA $1 / 2$ mutation, and contralateral symmetrization was not performed until the last follow-up visit. The indications for the technique were a moderate or large (cup size $\mathrm{B} / \mathrm{C}$ or above) and ptotic breast (Regnault classification type II-III, pseudoptosis and parenchymal maldistribution). The technique could provide both level I and level II volume displacement or even extreme OBCS if it was necessary. [22]

All the preoperative drawings and operations were carried out by two qualified (EBSQ) breast and plastic surgeons based on the decision of the multidisciplinary team.

The diagnosis of breast cancer, additional staging examinations, and follow-up of the patients were performed in accordance with the institutional protocol based on the actual ESMO guidelines. [37]

At the time of the study, a tumour-free resection margin of at least $1 \mathrm{~mm}$ was considered a microscopically free surgical margin (for invasive and in situ cancers as well), except the posterior and anterior margins if the surgery was performed with the maximally allowed radicality. After January 2015, the minimal surgical margin for invasive tumours was modified to "no cells on the inked surface", but a free margin of at least $1 \mathrm{~mm}$ remained an unmodified criterion for DCIS.

Non-palpable tumours were removed with the ROLL technique supplemented with an intraoperative mammography examination. 
Intraoperative frozen sectioning was not applied routinely for palpable tumours. In the case of SLNB, intraoperative imprint cytology was applied.

All of the analysed cases underwent whole-breast RT, with an overall dose of 50/2 or 40.05/2.67 Gy (external beam, 6-MV photon irradiation), and additional tumour bed boost irradiation (16/2 or 10/2.5 Gy) and/or axilla and supraclavicular irradiation if necessary.

Level I-III ALND was performed in patients with metastatic SLNs based on imprint cytology and in patients with unidentified SLN and clinically node-positive cases. After 1 January 2015, ALND was omitted by limited axillary metastases according to the study criteria of ACOSOG Z0011 [33] and OTOASOR. [34] In selected cases, patients with metastatic axillary SLN were treated with axillary and supraclavicular RT.

The database included each patient's age, BMI, smoking habits, diabetic co-morbidity, cup size, surgical technique, type of axillary surgery, specimen weight, rate and type of completion surgery, and operative time. The database also included the clinical and pathological TNM stage ( $7^{\text {th }}$ Edition) [35], histological tumour type, hormone receptor status, HER-2 receptor status, Grade, Ki67 value, molecular subtype and nature of the microscopic surgical margin. The type and initiation time of the adjuvant treatments, follow-up time and oncologic status of the patients were assessed.

The postoperative complications were divided into two categories. Minor complications included infections treated with antibiotics, haematoma, seroma, partial skin/NAC necrosis, limited fat necrosis, wound dehiscence and lymphoedema (redness of the skin lasting for more than 3 weeks) that healed spontaneously. Complications requiring surgical intervention were classified as major complications, including haematoma, chronic infection and seroma (lasting for more than 2 weeks following the removal of the surgical drain), extended fat necrosis, partial skin/NAC necrosis and wound dehiscence.

The final subjective and objective aesthetic outcomes were assessed at the $6^{\text {th }}$ postoperative month following the therapeutic OBCS and the immediate symmetrization or six months later if symmetrization was delayed.

To assess the aesthetic results, a 5-point Likert scale was used to judge the statement.

The overall aesthetic outcomes were classified objectively based on photo documentation using the BCCT.core software (version 20). [38] BCCT.core software provided automated measurements using digital marks to establish a 4-point classification scale (1: excellent, 2: good, 3: fair, 4: poor).

Collected data were analysed using Statistica 12.0 software. 
To determine the mean and median values of the recorded factors, descriptive statistics and the Wilcoxon signed-rank test were used. Data showing a non-normal distribution were analysed by the Mann-Whitney U test. Survival intervals were analysed using the KaplanMeier method and log-rank statistics. Correlations between active smoking, diabetic comorbidity, BMI and the occurrence of minor as well as major complications were statistically analysed using Pearson's chi-square or Fisher's exact test. Statistical significance was accepted when $\mathrm{p}<0.05$.

\section{Surgical technique of the central pedicled, modified Wise-pattern OBCS}

Before the operation, preoperative drawings in the standing position were generated. (Figure 3.a) A single dose of antibiotic (cefazolin or ciprofloxacin) was administered 30-60 minutes before surgery. After prepping and draping, along the incision lines, the subdermal plexus was infiltrated by a $0.5 \%$ solution of epinephrine and lidocaine.

Then, the NAC was marked by the appropriately sized $(35-45 \mathrm{~mm})$ areola marker, and the epidermis was transected along the incision line (except the skin of the neo-areola). Before cutting through the full thickness of the skin, it was best to de-epithelialize at least a 5-10mm-wide zone of every skin edge to avoid necrosis of the marginal line. The next step was de-epithelization of the preoperatively marked skin area on the lower breast pole. (Figure 3.b) The de-epithelized dermis was transected 5-10 $\mathrm{mm}$ from the markings along the vertical line with an electrosurgical device, and the transection was continued on the lower horizontal and distal wound edges in the IMF. In case of a modified Wise-pattern OBCS technique, it was necessary to leave the dermis intact surrounding the NAC (with at least a 10-mm margin), facilitating its blood supply from the subdermal plexus. On the vertical wound edges elevated by skin hooks, the dissection was performed over the layer of superficial fascia in the lamina anterior toward the superficial fascia of the pectoral major muscle in both the medial and lateral directions. (Figure 3.c)

Considering the size and location of the tumour, wide excision or quadrantectomy was performed. (Figure 3.d) Following the removal of the tumour, the tumour was conventionally orientated, and the cavity was marked with seven titanium clips. After taking out the specimen, the gloves and used instruments were changed according to general surgical principles.

Next, the central and surrounding flaps were dissected to the surface of the pectoral major muscle, leaving well-vascularized flaps. By modifying the classic Wise-pattern 
mastopexy, the mobility of the central glandular area was significantly increased by transecting the whole inferior dermal pedicle above the IMF by $5-10 \mathrm{~mm}$ with a slight downward inclination of the diathermy. (Figure 3.e) After transacting Scarpa's fascia, the perforating vessels were visible at this level and should not be harmed. (Figure 3.f) With the aforementioned manoeuver, the residual breast tissue and NAC were supplied by the perforating vessels of Würinger's septum [39,40], allowing the central glandular area (5-6 $\mathrm{cm}$ ) to slide and rotate into any quadrant without tension. (Figure 3.e) The vascular supply of the medial and lateral dermal flaps was derived from the perforators located superiorly in the $2^{\text {nd }} / 3^{\text {rd }}$ intercostal space and medially from the parasternal perforators located in the $2^{\text {nd }}$ and/or $3^{\text {rd }}$ intercostal spaces, as well as from the supplying vessels from the lateral and axilla. The defect caused by the removal of the tumour was easily closed by surrounding parenchyma pillars using simple interrupted 2.0 absorbable sutures.

Prior to wound closure, a $16 \mathrm{Ch}$ suction drain was placed from a separate orifice. The first and most important suture was the suture attaching the medial and lateral dermoglandular flaps with the appropriate edge of the IMF. The central dermoglandular flap, either with or without a preserved skin island, could be transposed into the tissue defect and anchored with absorbable sutures if necessary. (Figure 3.g) Next was the approximation and closure of the dermis and subcutaneous tissue with simple interrupted absorbable sutures. Monofilament continuous 4.0 non-absorbable sutures were used for skin closure for the periareolar wound and continuous 3.0 non-absorbable sutures for the horizontal and vertical incisions in the dual layer. (Figure 3.h) SLNB or ALND was performed from a separate incision after the OBCS.

Finally, the wounds were coated with Bactroban ${ }^{\circledR}$ gel and covered with semipermeable Mepore $^{\circledR}$ dressing. In the case of immediate symmetrization, the same reduction mammoplasty was performed on the contralateral breast. 
Figure 3. Pictures illustrating the surgical steps of the central pedicled, modified Wise-pattern OBCS

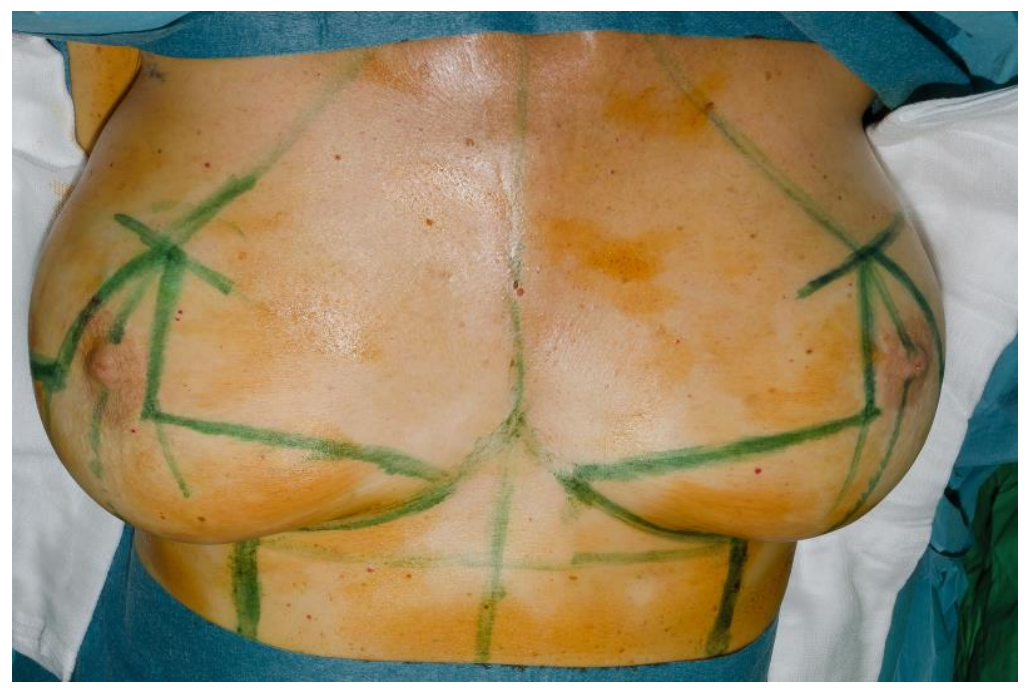

Figure 3.a Preoperative markings of a modified Wise-pattern therapeutic mammoplasty

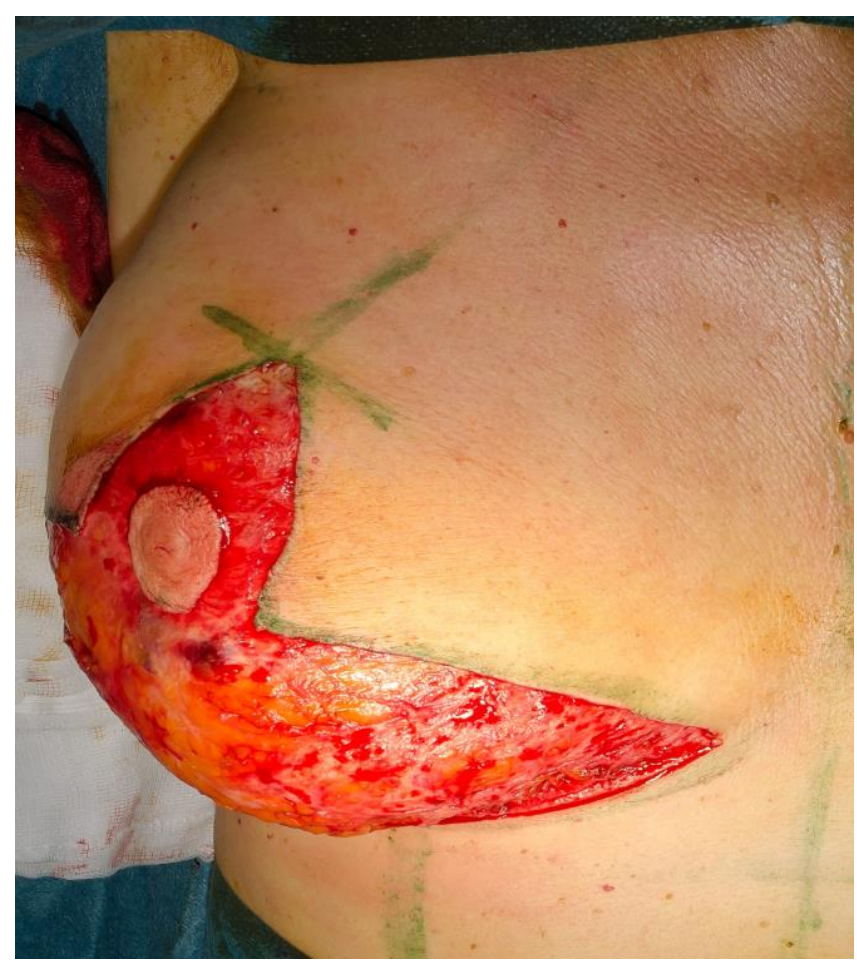

Figure 3.b De-epithelization of the periareolar skin area and the lower pole of the breast 


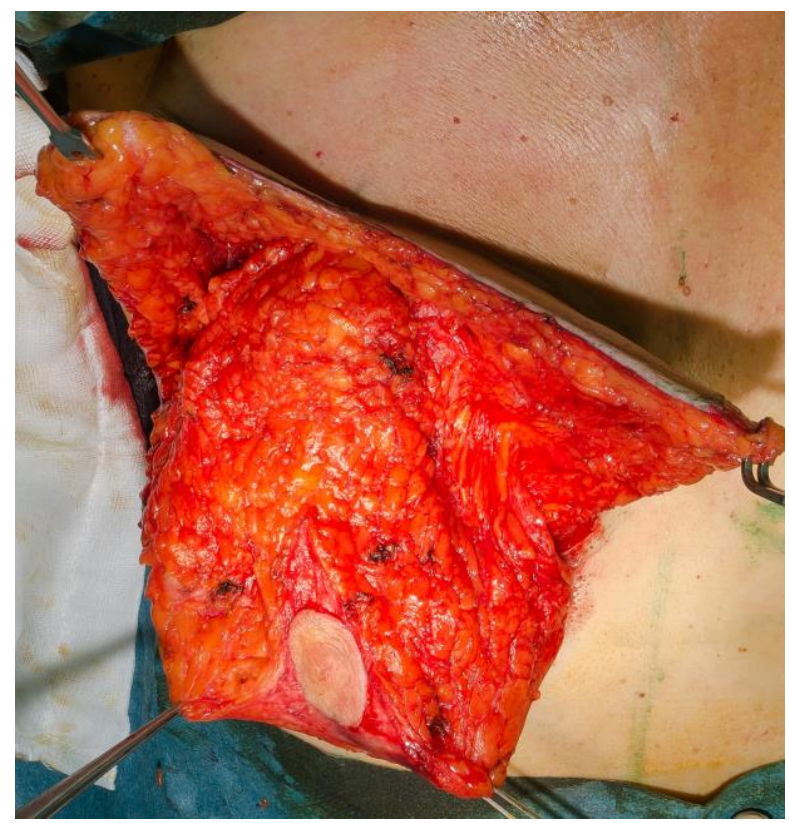

Figure 3.c Dissection of the medial and lateral dermal flaps from the parenchyma. At this step the vascular supply of the parenchyma is based on the peforator vessels running in the Würinger's septum and the subdermal plexus of the inferior pedicle

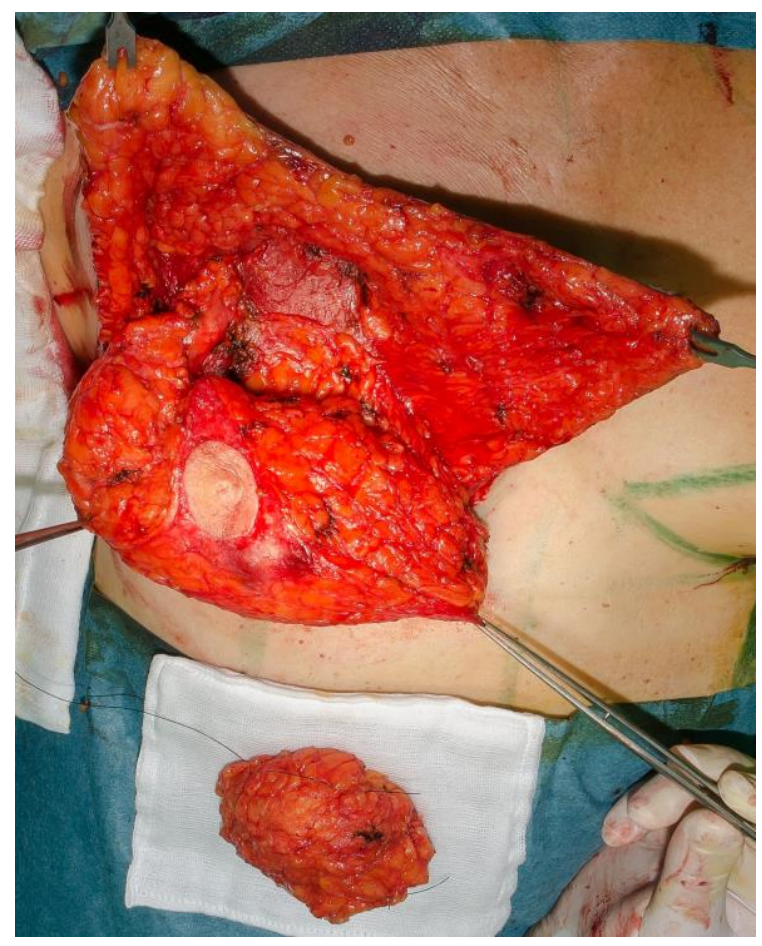

Figure 3.d The cT2N0M0, luminal-A, invasive ductal carcinoma (largest diamater 45 $\mathrm{mm}$ ) located in the upper pole of the right sided breast has been excised from the skin up to the pectoral major muscle, from the perifery to the retroareolar area in a slice of cake form. Specimen is orientated for histology 


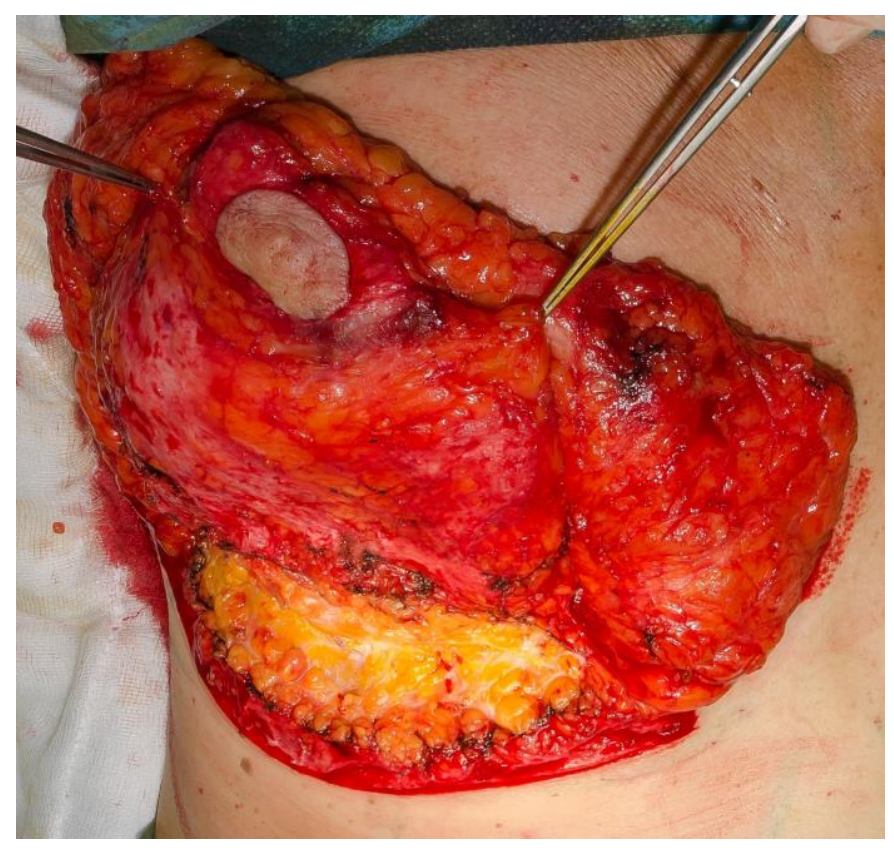

Figure 3.e By modifying the classic Wise-pattern mastopexy, the mobility of the central glandular area was significantly increased by transecting the whole inferior dermal pedicle above the IMF by 5-10 $\mathrm{mm}$ with a slight downward inclination of the diathermy. The residual breast tissue and NAC were supplied by the perforating vessels of Würinger's septum allowing the central glandular area $(5-6 \mathrm{~cm})$ to slide and rotate into the large defect $(95 \times 60 \mathrm{~mm})$ of the upper pole of the breast without tension

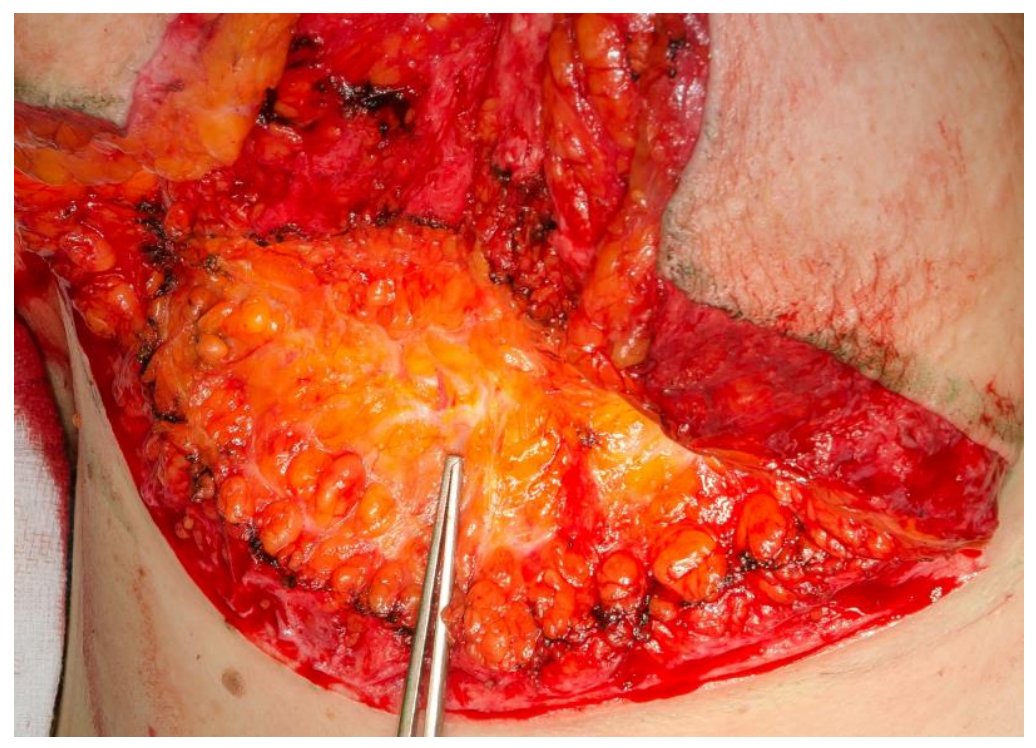

Figure 3.f Perforating vessels located just below the Scarpa's fascia should be preserved. 


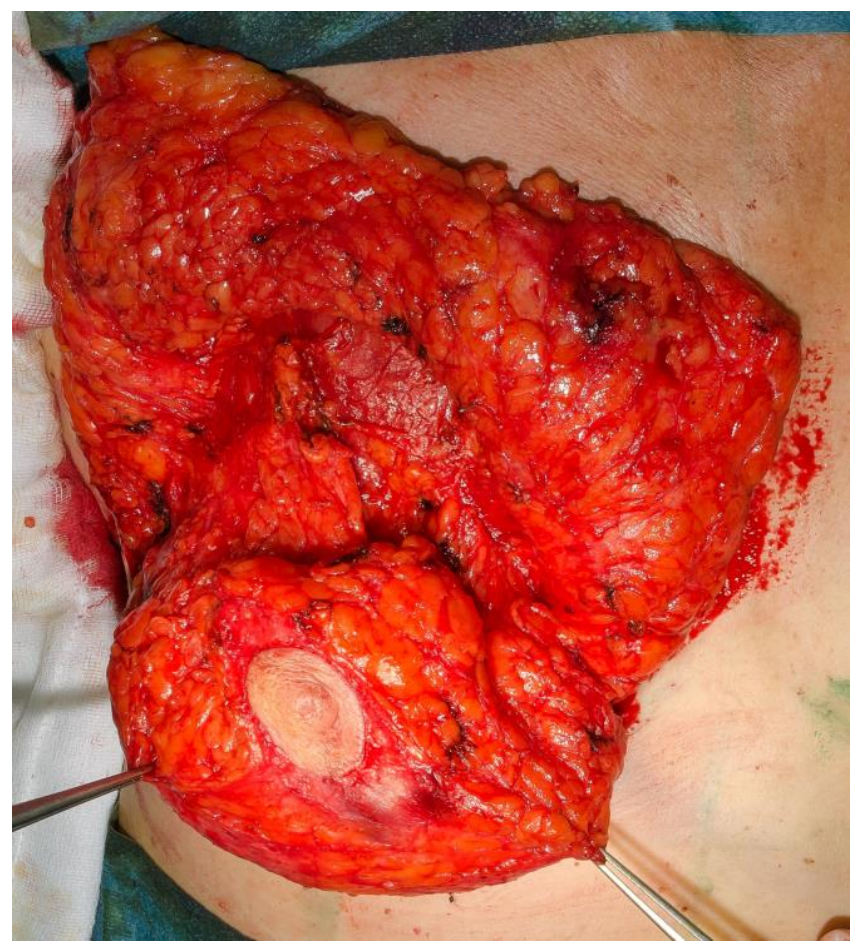

Figure 3.g Central pedicled parenchyma and the NAC can be transposed easily to the upper pole or to any quadrant of the breast with excellent vascular supply. Well preserved dermis around the NAC is mandatory to the viability of the remaining tissue

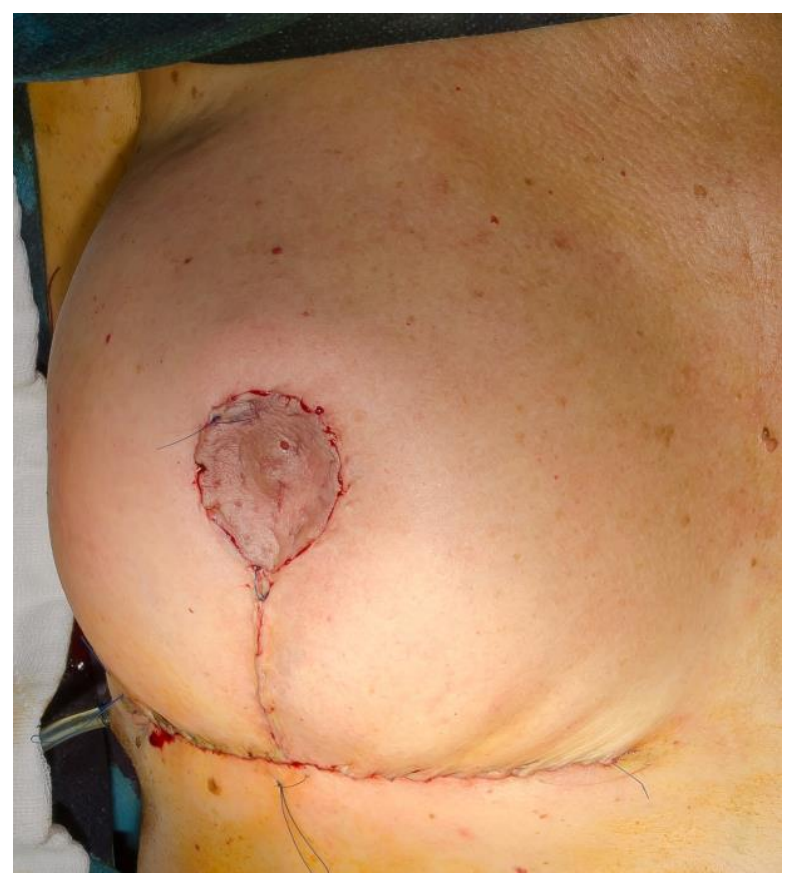

Figure 3.h Final cosmetic outcome following a step by step closure of the tissue layers. Well vascularised dermal flaps and NAC are visible 


\subsection{Evaluation of the modified Regnault "B" technique as a standard Level II OBCS.}

\section{A retrospective clinico-pathological and aesthetic study of 215 breast cancer patients}

This retrospective clinicopathological study included 227 stage 0 to stage III breast cancer cases operated with modified Regnault "B" oncoplastic breast conserving technique at the Department of Breast and Sarcoma Surgery of the NIO and was analysed based on a prospectively managed institutional database from March 2012 to October 2018. The study was approved by the institutional research ethics committee.

Patients were excluded as follows: if the patient did not want to participate in the study, did not cooperate in cosmetic outcome surveys, if the oncological follow up was performed in another institute, or if the medical history included previous breast surgery.

The surgeries were performed mainly on medium and/or large (cup sizes B-D) breasted patients with moderate to severe breast ptosis (Regnault classification Grade II-III, pseudoptosis).

The indication for the surgical procedure was Level II OBCS or complete quadrantectomy. After a multidisciplinary Breast Committee decision, surgical planning followed by the surgical procedure was carried out by two dedicated breast surgeons (ESSO/UEMS/EBSQ).

Diagnostic tests for breast cancer, imaging tests for staging, required multidisciplinary oncological therapy and follow-up were performed according to the current institutional protocol, which was determined according to the current recommendations of the ESMO and met the recommendations of the $2^{\text {nd }}$ and $3^{\text {rd }}$ Breast Cancer Consensus Conference. [41-44]

Breast diagnostic examinations and radiological follow-up were performed by radiologists with distinct license who are specialised in breast diagnostics and included physical examinations with complex imaging techniques (chest X-ray and ultrasound with mammography). In case of suspected malignancy, core biopsy or fine-needle aspiration biopsy was taken. Magnetic resonance imaging was performed in the presence of invasive lobular carcinoma, multifocal breast cancer or in case of inconsistencies between the complex imaging techniques and the clinical findings. [45]

The indication for primary systemic treatment (PST) during the study period was from cT2 and cN0 or c/pN1 and cT1-4/N2 status depending on the biological subtype. Based on the biological subtype, PST was used in chemosensitive tumours even in cNO (basallike/triple-negative (TN) or HER2-positive breast cancer). If there was a potential for BCS, a clip marker was used if the tumour did not contain microcalcifications and radiologically complete regression (CR) was expected. $[41,42,46]$ 
Palpable tumours were removed by excision with a minimum of $10 \mathrm{~mm}$ macroscopically intact margin. Non-palpable tumours were removed with preoperative ROLL technique followed by intraoperative specimen mammography/US control.

During the study period, in case of invasive and DCIS, the $1 \mathrm{~mm}$ microscopically tumour-free surgical margin represented the clear surgical margin as well, except for the posterior and anterior directions, if the resection included the superficial pectoral fascia in the deep and anterior directions. As of January 2015, the free surgical margin for invasive tumours was the tumour cell-free ink-marked surgical margin, whereas for DCIS the minimum requirement was 2 but at least $1 \mathrm{~mm}$ surgical margin.

Until 1 January 2015, level I-III ALND was performed when the SLN was positive by imprint cytology, histology, or the SLN could not be localised technically or in cases of cN1. As of January 2015, according to the criteria of the ACOSOG Z 0011 clinical study [47] $[\leq \mathrm{cT} 2$, cN0, pN1 (max. 1-2 positive lymph nodes)] cases, imprint cytology was no longer performed during surgery, as from this time ALND, - completing in case of limited regional lymph node metastasis - was not performed. In these cases, the axillary and supraclavicular regions were irradiated.

Histological examination of the removed specimen(s) was performed by a pathologist with routine consultation. The histological report included the number, size and position of the tumour(s) removed, the number of removed and metastatic lymph nodes, the size of the largest metastasis (isolated tumour cells, micrometastasis between 0.2 and $2 \mathrm{~mm}$ or macrometastasis above $2 \mathrm{~mm}$ ). The report also included tumour histological type, extensive intraductal component, multifocality, histological grade based on mitotic index and nuclear grade, surgical margins to the tenth of a millimetre, lymphovascular invasion, the presence of necrosis in the invasive component, Ki67 percentage, and other prognostic/predictive parameters such as ER, PR and HER2 status. In case of uncertain HER-2 status, HER2 gene amplification was determined by FISH (fluorescent in situ hybridisation) [48]. On the basis of the histology report, the oncotherapy committee decided on further oncology treatments.

Chemotherapy treatments in PST or adjuvant form during the study period were based on AC, EC, ADM-TXT, EPI-TXT, and A+TAX therapy. Triple-negative, HER2-positive, or higher-risk HER2-negative diseases (>20\% Ki67) indicated chemotherapy. In case of a hormone receptor-positive (oestrogen and/or progesterone) disease, premenopausal patients were treated with tamoxifen for at least 5 years following surgery. Considering the prognosis, this was supplemented by the use of luteinizing hormone-releasing hormone (LHRH) analogues for 2 to 5 years. In case of HER2 positivity, adjuvant trastuzumab complemented 
chemotherapy once a week and then every 3 weeks for a total of one year. [49] If neoadjuvant treatment was used in case of HER2 positivity, dual HER2 blockade (trastuzumab and pertzumab) was the first treatment of choice in addition to chemotherapy.

Patients were irradiated based on 3D radiation planning. Adjuvant RT began within six to twelve weeks after surgery. In the case of BCS and if there was no evidence of distant metastasis, patients received a total dose of $25 \times 2$ Gy or $15 \times 2.67$ Gy breast irradiation. Selected patients were also subjected to interstitial, high dose-rate brachytherapy-, or prospective, clinical trial image-guided, intensity-modulated teletherapy accelerated partial breast irradiation. In case of close excision (intact surgical margin $<2 \mathrm{~mm}$ ), extensive intraductal component (EIC), and under 50 years of age, tumour bed boost RT was also used following basic-dose WBI. Supplemental irradiation was given as 10-16 Gy teletherapy (electron or photon) or 3 x 4.75 Gy brachytherapy boost.

Data processing was carried out retrospectively. The database contained the most important clinicopathological parameters of the tumour: histological type, grade, lymph node status, tumour size, specimen weight, immunohistochemical parameters, and TNM $\left(7^{\text {th }}\right.$ Edition). It further included the patient's age, BMI, smoking habits, diabetes and other important comorbidities, and bra size.

Regarding surgery, the table included the time of surgery, the time and type (reexcision or mastectomy) of the completion surgery, complications, and the adjuvant treatment starting date.

Postoperative complications were classified by the Clavien-Dindo classification. [50,51] Grade I complications did not require medical or surgical intervention (minor inflammation, hematoma or suffusion not requiring surgery, seroma, partial skin/NAC necrosis, limited fat necrosis, wound healing problem, and lymphedema). Grade II complication is a Grade I complication listed above that requires medical or surgical intervention (antibiotic therapy, resuturing due to wound healing problem, or repeated puncture due to chronic seroma). Grade III complications require invasive surgery (hematoma evacuation, chronic inflammation that requires reopening, extensive fat necrosis, complete skin/NAC necrosis and dehiscence). During Grade IV complication, a transient organ failure was recorded. Grade V complication occurs when complications lead to death.

Patients' quality of life was assessed using the BREAST-Q validated outcome measure, which scored on a scale of 1-100 on "satisfaction with breast appearance", "RT discomfort", "psychosexual well-being", and "physical well-being". Higher scores indicated a 
better quality of life. [52] Patients filled in the questionnaire before the surgery and 6 months after surgery.

The final subjective and objective aesthetic results were also evaluated after six months. Patients were photographed before surgery and afterwards at each oncological follow-up visit.

The subjective aesthetic result was analysed on a 5-point Likert scale. Results were integrated and averaged.

The objective aesthetic result was also evaluated using a validated BCCT.core computer program. [38] This software performed automated measurements based on the photo documentation and gave a 4-point rating (1: excellent, 2: good, 3: fair, 4: poor). The results were statistically analysed.

\section{Surgical technique of the modified Regnault "B" OBCS}

Based on preoperative surgical planning in standing position, the operation starts with an "S"-shaped incision from the areola to the direction of the axilla and a periareolar incision for NAC medialisation.

The depth of the incisions is yet restricted to the epidermal layer and periareolarly, which is followed by de-epithelialisation of the skin above the tumour in the upper outer quadrant. If needed, it can be removed along with the skin above the tumour serving as anterior margin according to quadrantectomy. (Figures 4.a and 4.b) In case of broad excision, the dermal layer will be cut through after de-epithelialisation at the right position in "S"-shape and periareolarly in "C"-shape. The excision of the parenchyma is performed up to the pectoral fascia. The incision has the advantage that SLNB and further required axillary intervention can also be carried out from this approach without any separate skin incision. (Figures 4.c and 4.d) Following marker clip insertion into the tumour bed, the breast parenchyma is reshaped by rotating the voluminous lower outer quadrant of the breast as dermoglandular flap pedicled with the perforator vessels into the defect of the upper outer quadrant. For this, a curved incision is made in the IMF of the breast, then the parenchyma and the Scarpa's fascia is cut in a plane tilted $45^{\circ}$ outwards from the tumour cavity. Thereby the dermoglandular flap of the lower outer quadrant reaches an extraordinary mobility of even 7 to $8 \mathrm{~cm}$ and can fill the tumour bed without any tension.

The blood supply of the dermoglandular flap is provided by the perforator vessels of the horizontally running fascial duplication Würinger's septum. Their dissection may lead to 
ischaemia of the parenchyma and the skin, mainly on the distal part of the flap. After tensionfree rotation of the dermoglandular flap into the upper outer quadrant, the adaptation of parenchymal pillars will be performed with absorbable sutures over a drain. (Figures 4.e-g) The so re-shaped breast clearly requires NAC medialisation due to radial shortening of the "S"-shaped scar (on average 5\% to 15\%), thereby it will remain in its original position on the breast after recovery due to the sum of the two vectors, preventing axillary malpositioning. For lateral matrix rotation, the lengths of the two wound edges of the incision in the IMF will differ due to the rotation of the lower outer quadrant, resulting in congestion of the skin under the axilla. This unfavourable aesthetic result may be easily solved either by "consuming" the difference of the wound edges i.e. alignment of a shorter segment of the shorter inner wound edge with a longer segment of the outer wound edge by sutures, or by excision of the Burrow's triangle (skin and subcutaneous excision in order to avoid tissue congestion upon flap rotation/transposition). With an inverted $\mathrm{Y}$ suture in the axilla, a few $\mathrm{cm}$ and tissue amount also displaceable into the defect can be gained. It is important that the inner absorbable adaptive sutures are not drawn too much into the lower outer quadrant of the often thin dermoglandular flap's parenchyma because sutures may impair blood supply. The modified Regnault "B" lateral OBCS leaves radial scars in the periareolar region and the upper outer quadrant, and one in the IMF as natural fold, which will become nearly invisible after WBI. (Figures 4.h-i) 
Figure 4. Illustrating the surgical steps of the modified Regnault " $\mathrm{B}$ " oncoplastic breastconserving surgery technique
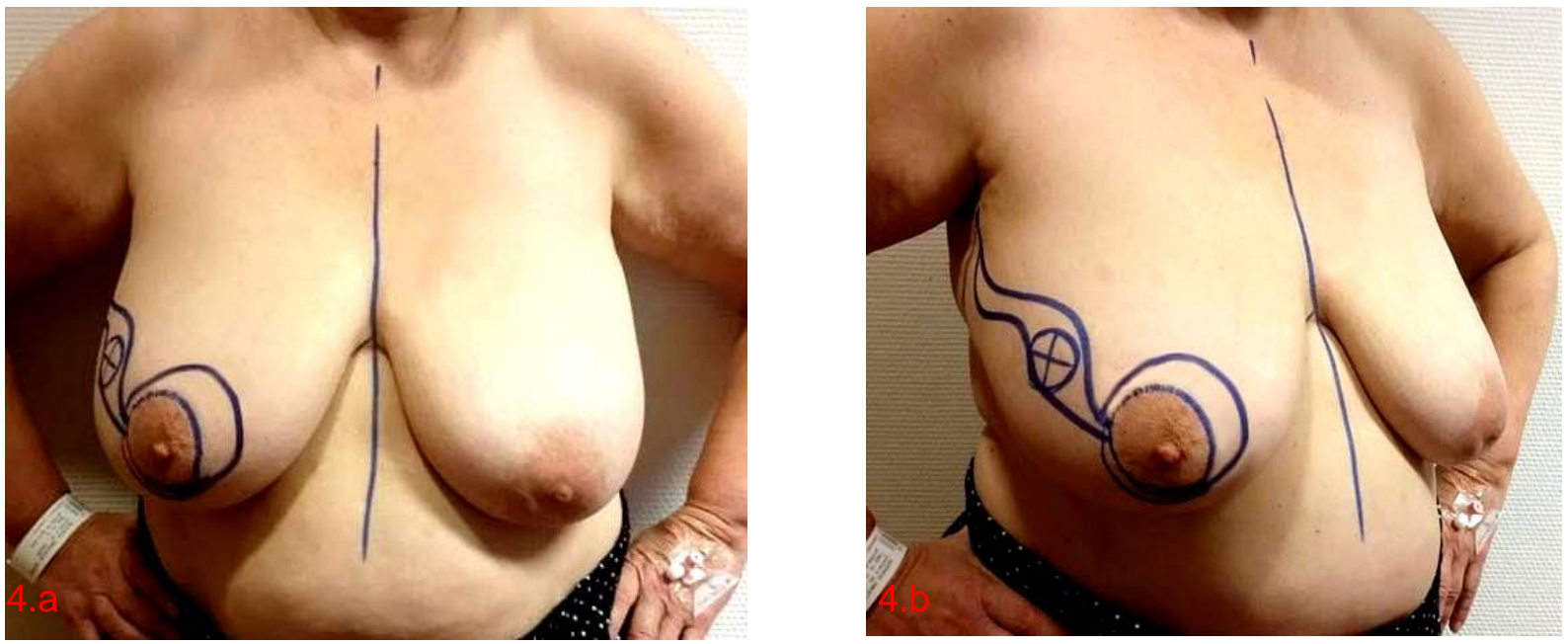

Figure 4.a-b: Surgical planning of the modified Regnault "B" OBCS technique due to a cT2N0 M0, luminal-A, invasive ductal carcinoma located in the upper-outer quadrant of the right sided breast
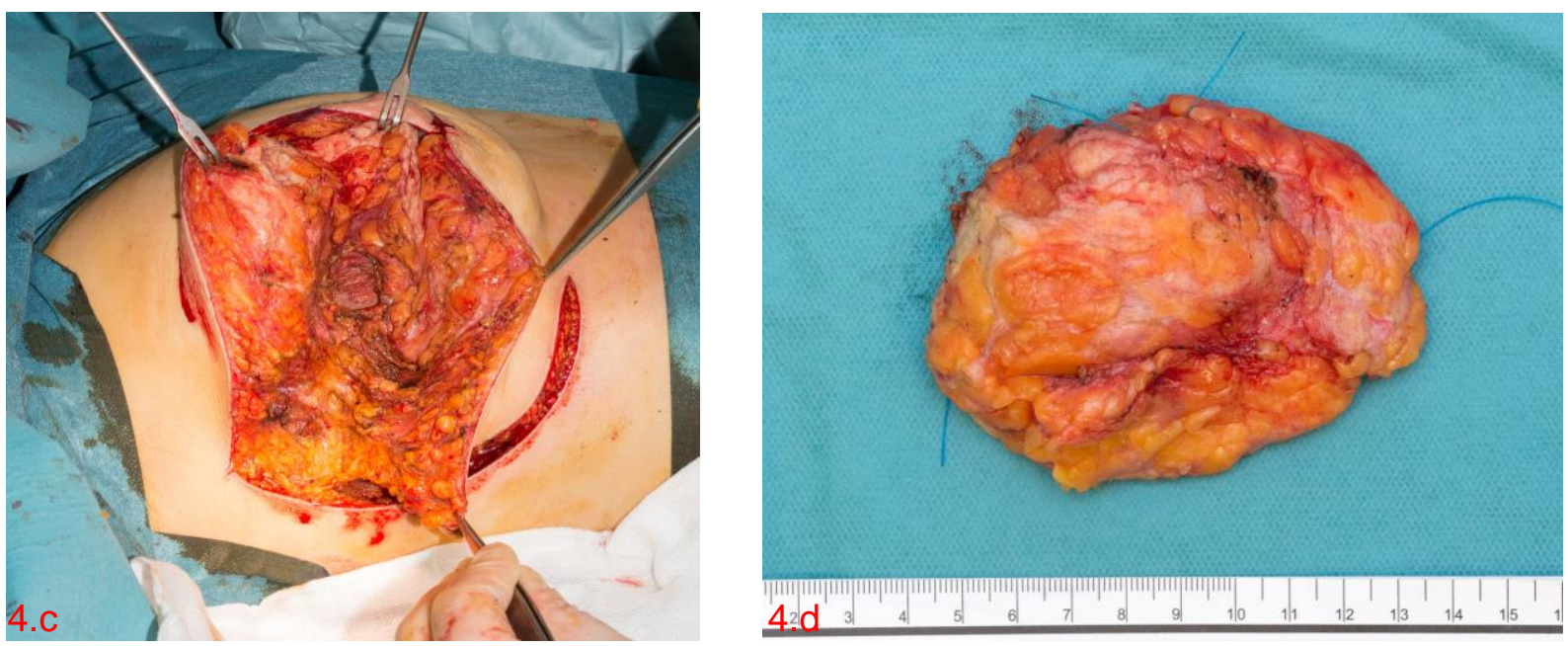

Figure 4.c-d.: Illustraing the quadrantectomy and the orientation of the specimen 

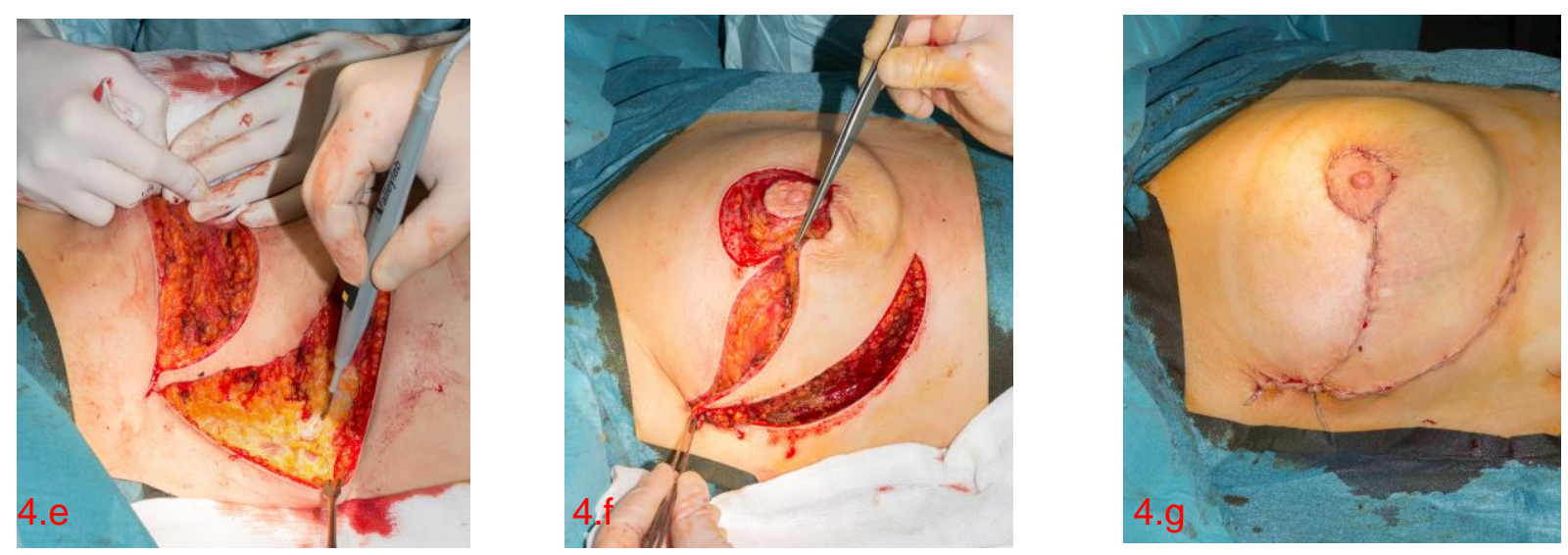

Figure 4.e-g.: Followed by the quadrantectomy, the additional skin incision was made in the IMF. As the next step after desepithelisation of the periareolar skin and medialisation of the $\mathrm{NAC}$, the dermoglandular flap was rotated into the upper outer quadrant and the adaptation of parenchymal pillars was performed with absorbable sutures over a suction drain. As the final step the closure of the skin was done in two layers with non-absorbable continous sutures
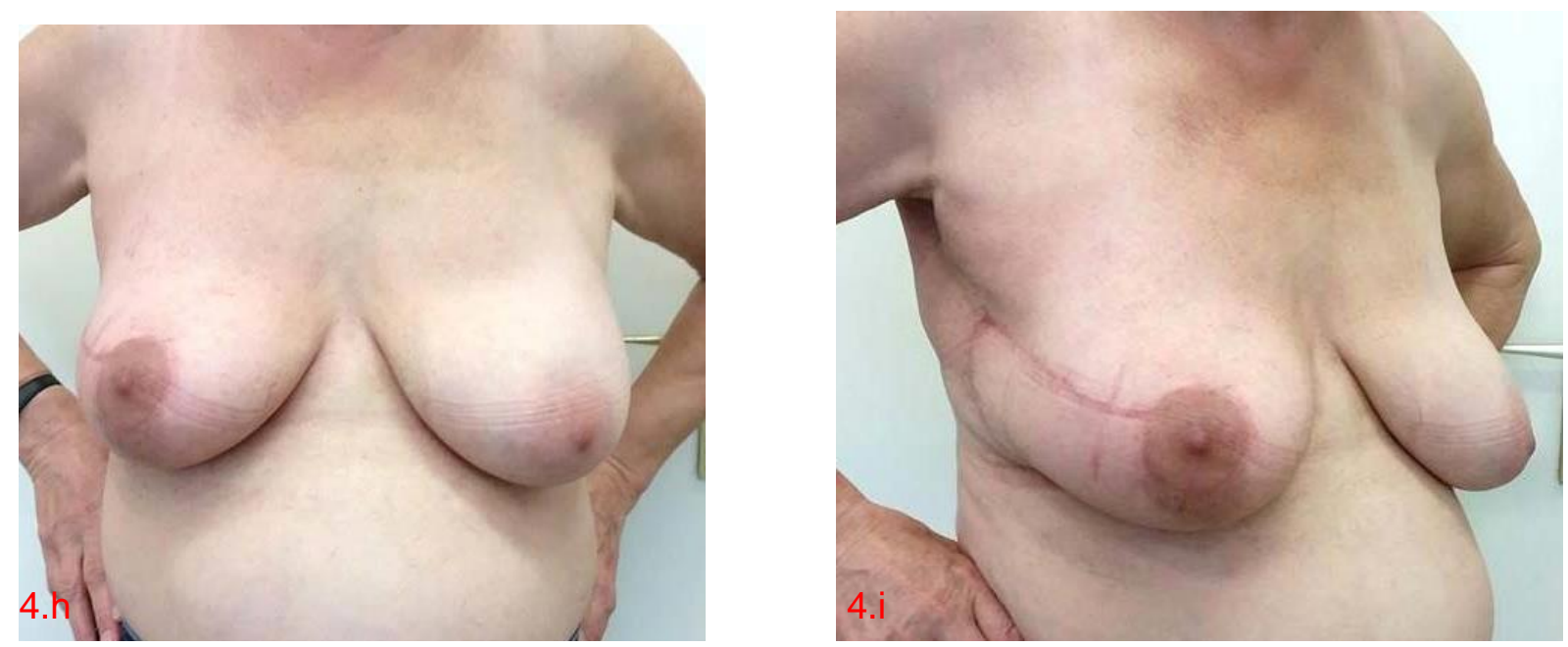

Figure 4.h-i.: The modified Regnault "B" lateral OBCS leaves radial scars in the periareolar region and the upper outer quadrant, and one in the IMF as natural fold, which will become nearly invisible after WBI. 


\section{RESULTS}

4.1 Long-term comparison of clinicopathological, cosmetic and quality of life outcomes in 700 oncoplastic and conventional breast-conserving surgery cases: A single-centre retrospective study

Fifty-six patients were lost to follow-up. The oncologic follow-up of 16 patients was performed in another institute, 14 patients did not want to participate in the evaluation of the cosmetic and quality of life outcome measurements and in 26 patients, an immediate breast symmetrisation was performed with the therapeutic surgery. In total, 350 breast cancer patients were in the OBCS group, and 350 patients were in the CBCS group.

The mean follow-up time was 51 months (range: 12-95 months) for the OBCS group and 52 months (range:12-96 months) for the CBCS group.

\subsubsection{Patient and tumour characteristics}

The patient characteristics are summarized in Table 1.

Table 1. Patients' characteristics

\begin{tabular}{|c|c|c|c|}
\hline Variable & $\begin{array}{c}\text { OBCS group } \\
\begin{array}{c}(\mathbf{n}=\mathbf{3 5 0}) \\
\text { n }(\%)\end{array}\end{array}$ & $\begin{array}{c}\text { CBCS group }(n=350) \\
n(\%)\end{array}$ & p-value \\
\hline \multicolumn{4}{|l|}{$\begin{array}{l}\text { Patients' } \\
\text { characteristics }\end{array}$} \\
\hline mean age & $58(31-85)$ & $59(29-86)$ & NS \\
\hline$B M I$ & $23.3(17.1-30.4)$ & $22.9(16.9-31.3)$ & NS \\
\hline active smoking & $37(10.57)$ & $41(11.71)$ & NS \\
\hline diabetic co-morbidity & $16(4.57)$ & $20(5.71)$ & NS \\
\hline \multicolumn{4}{|l|}{ Cup size } \\
\hline$A-B$ & $116(33.14)$ & $237(67.71)$ & 0.001 \\
\hline$C-F$ & $234(66.86)$ & $113(32.29)$ & 0.001 \\
\hline
\end{tabular}

CBCS: conventional breast conserving surgery; OBCS: oncoplastic breast conserving surgery; NS: not significant

The groups were homogenous in terms of age, BMI, active smoking status and diabetic comorbidity, while the cup sizes were significantly larger $(\mathrm{p}=0.001)$ in the OBCS group than in the CBCS group. The tumour characteristics are detailed in Table 2. 
Table 2. Comparison of the tumour characteristics of the OBCS and the CBCS groups

\begin{tabular}{|c|c|c|c|}
\hline Variable & $\begin{array}{c}\text { OBCS group }(n=350) \\
n(\%)\end{array}$ & $\begin{array}{c}\text { CBCS group }(n=350) \\
n(\%)\end{array}$ & p-value \\
\hline \multicolumn{4}{|c|}{ 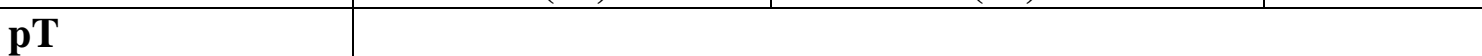 } \\
\hline pTis & $22(6.29)$ & $30(8.57)$ & NS \\
\hline pTla-c & $210(60.00)$ & $226(64.56)$ & NS \\
\hline$p T 2$ & $88(25.14)$ & $91(26.00)$ & NS \\
\hline pT3 & $2(0.57)$ & $1(0.29)$ & NS \\
\hline pT4 & $1(0.29)$ & $1(0.29)$ & NS \\
\hline ypT0 & $15(4.28)$ & $0(0.0)$ & 0.001 \\
\hline ypTla & $9(2.57)$ & $1(0.29)$ & 0.001 \\
\hline ypT1c & $2(0.57)$ & $0(0.0)$ & NS \\
\hline ypT2 & $1(0.29)$ & $0(0.0)$ & NS \\
\hline \multicolumn{4}{|l|}{ pN } \\
\hline$p N O$ & $237(67.71)$ & $317(90.57)$ & 0.013 \\
\hline$p N 1$ & $67(19.15)$ & $25(7.14)$ & 0.011 \\
\hline$p N 2$ & $16(4.58)$ & $6(1.71)$ & NS \\
\hline$p N 3$ & $3(0.85)$ & $1(0.29)$ & NS \\
\hline ypNO & $17(4.86)$ & $0(0.0)$ & 0.001 \\
\hline$y p N 1$ & $7(2.00)$ & $1(0.29)$ & NS \\
\hline$y p N 2 a$ & $3(0.85)$ & $0(0.0)$ & NS \\
\hline \multicolumn{4}{|l|}{ Histological type } \\
\hline$I D C$ & $271(77.42)$ & $277(79.14)$ & NS \\
\hline$I L C$ & $35(10)$ & $21(6.00)$ & NS \\
\hline Other & $22(6.28)$ & $22(6.28)$ & NS \\
\hline In situ component & $170(48.57)$ & $124(35.42)$ & 0.012 \\
\hline \multicolumn{4}{|l|}{ Immunhistology } \\
\hline$E R+$ & $271(77.42)$ & $303(86.57)$ & NS \\
\hline$P R+$ & $119(34.00)$ & $143(40.85)$ & NS \\
\hline$H E R-2+$ & $19(5.42)$ & $5(1.42)$ & NS \\
\hline Triple negative & $38(10.85)$ & $12(3.42)$ & 0.004 \\
\hline$K i 67 \geq 20 \%$ & $130(37.14)$ & $79(22.57)$ & 0.001 \\
\hline \multicolumn{4}{|l|}{ Grade } \\
\hline$I$ & $107(30.57)$ & $94(26.85)$ & NS \\
\hline II & $127(36.28)$ & $139(39.71)$ & NS \\
\hline III & $89(25.42)$ & $87(24.85)$ & NS \\
\hline \multicolumn{4}{|l|}{ pStage } \\
\hline 0 & $27(7.71)$ & $30(8.57)$ & $\mathrm{NS}$ \\
\hline$I$ & $165(47.14)$ & $211(60.28)$ & 0.02 \\
\hline II & $137(39.14)$ & $100(28.57)$ & 0.035 \\
\hline III & $21(6.00)$ & $9(2.57)$ & NS \\
\hline
\end{tabular}

NS: not significant; IDC: invasive ductal carcinoma; ILC: invasive lobular carcinoma; ER: oestrogen receptor; PR: Progesteron receptor; HER-2: human epidermal growth factor receptor-2 
According to the data in Table 2, there were no significant differences between the two groups in terms of the pathological tumour size, tumour grade or invasive pathological subtype.

Compared to the CBCS group, the OBCS group had significantly more patients with pathological Stage II tumours ( $\mathrm{p}=0.035)$ and more patients with $\mathrm{pN} 1$ status $(\mathrm{p}=0.011)$.

The number of patients with triple negative $(\mathrm{p}=0.004)$ and/or highly proliferative tumours (Ki67 $\geq 20 \%)$ was significantly higher $(\mathrm{p}=0.001)$ in the OBCS group than in the CBCS group.

Significantly more patients underwent neoadjuvant chemotherapy $(p=0.001)$ in the OBCS group than in the CBCS group.

The rates of adjuvant chemo- and biological therapy, RT and endocrine therapy were $40.57 \%, 100 \%$ and $82.85 \%$ in the OBCS group and $23.14 \%, 100 \%$ and $87.42 \%$ in the CBCS group. There was a significant difference in the number of patients who underwent chemoand biological therapy between the two groups $(\mathrm{p}=0.002)$.

\subsubsection{Type of surgery, operation time}

The techniques of the OBCS procedures are summarized in Table 3.

Table 3. Techniques of the OBCS procedures

\begin{tabular}{|l|c|}
\hline Oncoplastic techniques & n \\
\hline Therapeutic mammaplasty (modified, superior, inferior pedicle Wise-pattern) & 143 \\
\hline Dermoglandular rotation (medial, lateral mammoplasty) & 159 \\
\hline Periareolar (round block, omega) & 48 \\
\hline Total & 350 \\
\hline
\end{tabular}

Significantly more quadrantectomies were performed in the OBCS group $(p=0.001)$ than in the CBCS group ( $n=265$ vs. $n=159$ ), resulting a statistically significant difference $(\mathrm{p}=0.002)$ in the number of wide excisions ( $\mathrm{n}=85$ vs. $\mathrm{n}=191)$, which was the most common technique in standard BCS cases. However, there was no significant difference $(p=0.25)$ between the two groups in the number of ROLL techniques. In the OBCS group, ALND was performed in total of 72 cases, while in the CBCS group, only 18 patients were treated with ALND. Thus, the difference was statistically significant $(\mathrm{p}=0.001)$.

In relation to the operative times, the OBCS procedures required significantly longer operation times $(\mathrm{p}<0.01)$ than the CBCS techniques. The average operation time was 68 minutes for the OBCS group and 58 minutes for the CBCS group. 


\subsubsection{Volume of the specimens and tumour margins}

The median weight of the excised specimens in the OBCS group was $90 \mathrm{~g}$ (range: 4$529 \mathrm{~g}$ ), while in the CBCS group, it was found to be $63 \mathrm{~g}$ (range: 1.5-878 g) Thus, a significantly larger volume of breast tissue was excised during OPS than during standard BCS $(\mathrm{p}=0.001)$. In the OBCS group, the median microscopically tumour-free surgical margin was $8 \mathrm{~mm}$ (range: 0-21 mm), while in the CBCS group, it was $4.5 \mathrm{~mm}$ (range: 0-17 mm), resulting significantly wider clear surgical margins in OBCS group than in the CBCS group $(\mathrm{p}=0.010)$.

Due to positive or close surgical margins, 28 (8\%) completion surgeries were performed (19 [5.42\%] re-excisions and 9 [2.57\%] mastectomies) in the OBCS group, whereas in the CBCS group, $38(10.85 \%)$ patients required re-excision and $20(5.71 \%)$ patients needed mastectomies, resulting in a total of $58(16.57 \%)$ reoperations. The rate of completion surgery was significantly higher in the CBCS group than in the OBCS group $(\mathrm{p}=0.001)$.

\subsubsection{Complication and initiation time of adjuvant therapy}

There were 11 minor complications $(3.14 \%)$ and 9 major complications $(2.57 \%)$ requiring surgical intervention in the OBCS group, resulting in a total of 20 complications $(5.71 \%)$.

In the CBCS group, 23 (6.57\%) complications were identified, of which 11 (3.14\%) were minor and $12(3.42 \%)$ were classified as major.

The complications in both groups are summarized in Table 4.

Table 4. Comparison of the complication rate in the OBCS and CBCS group

\begin{tabular}{|c|c|c|c|c|}
\hline & \multicolumn{2}{|c|}{ OBCS group $(n=350)$} & \multicolumn{2}{|c|}{ CBCS group $(n=350)$} \\
\hline Complications & $\operatorname{minor}(\mathbf{n}, \%)$ & major $(n, \%)$ & $\operatorname{minor}(\mathrm{n}, \%)$ & major $(n, \%)$ \\
\hline seroma & $3(0.85)$ & $2(0.57)$ & $6(1.71)$ & $3(0.85)$ \\
\hline haematoma & $0(0.0)$ & $2(0.57)$ & $0(0.0)$ & $4(1.14)$ \\
\hline infection & $5(1.42)$ & $3(0.85)$ & $4(1.14)$ & $3(0.85)$ \\
\hline $\begin{array}{l}\text { skin/NAC } \\
\text { necrosis }\end{array}$ & $2(0.57)$ & $1(0.28)$ & $1(0.29)$ & $1(0.29)$ \\
\hline fat necrosis & $1(0.29)$ & $1(0.29)$ & $0(0.0)$ & $1(0.29)$ \\
\hline $\begin{array}{l}\text { Total } \\
\text { minor/major }\end{array}$ & $11(3.14)$ & $9(2.57)$ & $11(3.14)$ & $12(3.42)$ \\
\hline Overall & \multicolumn{2}{|c|}{$20(5.71)$} & \multicolumn{2}{|c|}{$23(6.57)$} \\
\hline
\end{tabular}


The median time to the initiation of the adjuvant treatment was 4.2 weeks (range: $4-12$ weeks) in the OBCS group and 4.1 weeks (4-12 weeks) in the CBCS group. In terms of complication rate and the initiation time of adjuvant therapy, significant differences were not observed between the two groups $(\mathrm{p}=0.31)$.

\subsubsection{Local and locoregional recurrence}

During the follow-up period, there were 7 (2.0\%) recurrences identified in the OBCS group, $4(1.14 \%)$ of which were local recurrences (LRs) and $3(0.85 \%)$ of which were locoregional recurrences (LRRs). In the CBCS group, 11 (3.14\%) LRs and 2 (0.57\%) LRRs with distant metastasis were identified, resulting in a total of $13(3.71 \%)$ recurrences. There were no statistically significant differences between the OBCS and the CBCS groups regarding the rates of $\operatorname{LR}(\mathrm{p}=0.29), \operatorname{LRR}(\mathrm{p}=0.31)$ and distant metastases $(\mathrm{p}=0.33)$.

Two patients in the CBCS group were not alive at the time of the last follow-up due to the progression of the disease.

\subsubsection{Aesthetic outcome and quality of life}

The median values of the aesthetic outcome score were significantly different between the two groups, with 4.4 points (range: $3-5$ ) in the OBCS group and 3.2 points (range: 1-5) in the CBCS group ( $\mathrm{p}=0.001)$.

In the OBCS group, the median value of the emotional functioning score was 91.6 (range: 50-100), whereas the median social functioning score was 83.4 (range: 33-100). The median body image score was 91.6 (range: 50-100).

In the CBCS group, the median value of the emotional functioning score was 83.4 (range: 50-100), whereas the median social functioning score was 75.0 (range: 50-100). The median body image score was 75.0 (range: 33-100). All the median scores of the aesthetic outcomes were significantly higher $(\mathrm{p}<0.01)$ in the OBCS group than in the CBCS group.

\subsection{Evaluation of the central pedicled, modified Wise-pattern technique as a standard level II oncoplastic breast-conserving surgery: A retrospective clinicopathological study of 190 breast cancer patients}

Seventeen patients were lost to follow-up. As a result, a total of 190 patients were enrolled and underwent therapeutic modified Wise-pattern OBCS. In 112 patients, immediate contralateral symmetrization was performed, while this procedure was carried out in a second 
stage in 74 patients. Four patients underwent therapeutic OBCS on both sides. The mean follow-up time was 43.9 months (range: 12-72 months).

\subsubsection{Patient and tumour characteristics}

The mean age of the patients was 56 years (range: 31-78 years). The mean BMI was $24.2 \mathrm{~kg} / \mathrm{m}^{2}$ (range: 17.9-34.4). Fifteen patients were active smokers, and 8 had diabetes as a co-morbidity.

The mean cup size, the affected side and the distribution of the tumours in each quadrant of the breast are summarized in Table 5.

The tumour characteristics are provided in Table 6.

Table 5. Summarizing the cup size, the affected quadrant and side of the breast

\begin{tabular}{|l|c|}
\hline Variable & $\mathbf{n}(\%)$ \\
\hline Side & $103(53.1 \%)$ \\
Left & $91(46.9 \%)$ \\
\hline Light & \\
\hline Uppation of the tumour & $89(45.9 \%)$ \\
Inner-lower & $22(11.3 \%)$ \\
Lower-outer & $35(18.0 \%)$ \\
Inner-upper & $25(12.9 \%)$ \\
Central & $23(11.9 \%)$ \\
\hline Cup size & \\
\hline B & $54(28.4 \%)$ \\
C & $88(46.3 \%)$ \\
D & $40(21.1 \%)$ \\
E & $7(3.7 \%)$ \\
F & $1(0.5 \%)$ \\
\hline
\end{tabular}


Table 6. Tumour characteristics

\begin{tabular}{|c|c|}
\hline Variable & n $(\%)$ \\
\hline \multicolumn{2}{|l|}{ pT } \\
\hline pTis & $21(10.6 \%)$ \\
\hline pTla-c & $85(42.9 \%)$ \\
\hline$p T 2$ & $66(33.3 \%)$ \\
\hline pT3 & $2(1.1 \%)$ \\
\hline урт0 & $11(5.5 \%)$ \\
\hline ypTla & $8(4.0 \%)$ \\
\hline ypTlc & $3(1.5 \%)$ \\
\hline ypT2 & $2(1.1 \%)$ \\
\hline \multicolumn{2}{|l|}{ pN } \\
\hline pNO & $115(58.1 \%)$ \\
\hline pNmi-1 & $48(24.3 \%)$ \\
\hline$p N 2$ & $8(4.0 \%)$ \\
\hline$p N 3$ & $3(1.5 \%)$ \\
\hline ypNO & $11(5.5 \%)$ \\
\hline ypN1 & $10(5.1 \%)$ \\
\hline ypN2a & $3(1.5 \%)$ \\
\hline \multicolumn{2}{|l|}{ Histological type } \\
\hline$I D C$ & 164 \\
\hline$I L C$ & 21 \\
\hline Other & 9 \\
\hline In situ component & 97 \\
\hline \multicolumn{2}{|l|}{ Immunhistology } \\
\hline$E R+$ & 162 \\
\hline$P R+$ & 150 \\
\hline$H E R-2+$ & 37 \\
\hline Triple negative & 28 \\
\hline$K i 67 \geq 20 \%$ & 75 \\
\hline \multicolumn{2}{|l|}{ Grade } \\
\hline$I$ & 40 \\
\hline II & 68 \\
\hline III & 65 \\
\hline \multicolumn{2}{|l|}{ pStage } \\
\hline 0 & 21 \\
\hline$I$ & 69 \\
\hline$I I$ & 90 \\
\hline III & 14 \\
\hline
\end{tabular}

IDC: invasive ductal carcinoma; ILC: invasive lobular carcinoma; ER: oestrogen receptor;

PR: progesteron receptor; HER-2: human epidermal growth factor receptor-2 
A total of $12.6 \%$ of the patients underwent neoadjuvant chemotherapy. The rates of adjuvant chemo- and biological therapy, RT and endocrine therapy were 43.7\%, $100 \%$ and $85.5 \%$, respectively. Furthermore, 68 patients received additional boost irradiation.

\subsubsection{Volume of the specimen and tumour margins}

The mean weight of the excised specimens was $129.8 \mathrm{~g}$ (range: 16-533 $\mathrm{g}$ ), and the mean pathological tumour size was $18.37 \mathrm{~mm}$ (range: 5-60 $\mathrm{mm}$ ).

The median microscopically free surgical margin was $7 \mathrm{~mm}$ (min.-max.: 0-19 $\mathrm{mm}$ ). Due to positive or close surgical margins, $11(5.78 \%)$ re-excisions and $2(1.05 \%)$ mastectomies were performed, resulting in $13(6.84 \%)$ reoperations in total.

\subsubsection{Complications and initiation time of adjuvant therapy}

In total, 45 complications (12.9\%) were recorded, including 33 minor (9.4\%) and 12 major $(3.4 \%)$ complications requiring surgical intervention. The complications are detailed in Table 7 regarding both the therapeutic and non-therapeutic sides.

The median time until the initiation of the adjuvant treatment was 4.9 weeks (range: 412 weeks).

Table 7. Summarizing the complications regarding both on the therapeutic and on the nontherapeutic side

\begin{tabular}{|l|c|c|c|c|}
\hline & \multicolumn{2}{|c|}{ Therapeutic side (n=194) } & \multicolumn{2}{c|}{ Non-therapeutic side (n=186) } \\
\hline Complications & minor $\mathbf{( n , \% )}$ & major $(\mathbf{n , \% )}$ & minor (n, \%) & major (n, \%) \\
\hline seroma & 2 & 0 & 1 & 0 \\
\hline haematoma & 1 & 3 & 0 & 2 \\
\hline infection & 2 & 2 & 2 & 1 \\
\hline wound dehiscence & 5 & 2 & 2 & 1 \\
\hline skin/NAC necrosis & 2 & 1 & 2 & 0 \\
\hline $\begin{array}{l}\text { redness } \\
\text { (lymphoedema) }\end{array}$ & 7 & 0 & 4 & 0 \\
\hline fat necrosis & 2 & 0 & 1 & 0 \\
\hline Total minor/major & $21(10.8 \%)$ & $8(4.1 \%)$ & $12(6.4 \%)$ & $4(2.1 \%)$ \\
\hline Overall & \multicolumn{4}{|c|}{$45(12.9 \%)$} \\
\hline
\end{tabular}

(NAC: nipple-areola complex)

\subsubsection{Local- and locoregional recurrence}

In the follow-up period, $11(5.8 \%)$ recurrences were identified, $6(3.2 \%)$ of which were LR, $3(1.6 \%)$ of which were LRR, and two (1.05\%) of which were a LRR with distant multiplex bone metastasises. The DFS and the OS rates were found to be $75.5 \%$ and $98.7 \%$, 
respectively. Two patients were not alive at the time of the last follow-up due to the progression of the disease.

\subsubsection{Aesthetic outcome}

The majority of the breast surgeons agreed with the statement "This case has an excellent aesthetic outcome", with a mean score of 4.1 (range: 1.8-5).

Evaluating the objective outcome by BCCT.core, the median value of the overall aesthetic outcome was 1.9 (range: 1-4).

\subsubsection{Operation time}

The mean operative time for bilateral cases was 119 minutes (range: 92-185) with SLNB or ALND.

The cases without contralateral symmetrization required a mean of 69 minutes (range: 42-102) with SLNB or ALND.

\subsubsection{Contralateral breast findings}

In two patients, the final histological results verified an extensive DCIS component, necessitating a skin-sparing mastectomy with delayed breast reconstruction using a submuscular tissue expander.

In two patients, following the symmetrizing reduction Wise-pattern surgery, lobular in situ cancer was verified as an accidental finding on the non-therapeutic side.

\subsection{Evaluation of the modified Regnault " $B$ " technique as a standard Level II} oncoplastic breast-conserving surgery. A retrospective clinico-pathological and aesthetic study of 215 breast cancer patients.

Of the 227 patients, 215 patients' data have been analysed, 12 patients were excluded from the study due to missing data.

\subsubsection{Patient and tumour characteristics}

Main patient characteristics and clinicopathological variables are presented in Table 8. Patients' mean age was 53 years (range: 29-81 years). Median follow-up period was 47 months (range: 7-85 months). PST was administered in 29 cases (13.5 \%). 22 patients declared themselves as active smokers, and 11 patients had diabetes in their medical history. 
Table 8. Patient's characteristics and clinicopathological parameters

\begin{tabular}{|c|c|}
\hline Patient number & 215 \\
\hline Age (median; range) years & $53(29-81)$ \\
\hline Height $(\operatorname{mean} \pm$ SD $) \mathrm{cm}$ & $168 \pm 6$ \\
\hline Weight (mean \pm SD) $\mathrm{kg}$ & $71 \pm 14$ \\
\hline BMI $($ mean \pm SD) & $23.9 \pm 6.4$ \\
\hline \multicolumn{2}{|l|}{ Side } \\
\hline Left & $112(52.1 \%)$ \\
\hline Right & $103(47.9 \%)$ \\
\hline \multicolumn{2}{|l|}{ Axillary surgery, n (\%) } \\
\hline SLNB & $181(84.2 \%)$ \\
\hline ALND & $34(15.8 \%)$ \\
\hline Clinical tumour size (mean \pm SD) $\mathrm{mm}$ & $26 \pm 13$ \\
\hline \multicolumn{2}{|l|}{ Bra Cup size } \\
\hline $\mathrm{A}$ & $12(5.6 \%)$ \\
\hline $\mathrm{B}$ & $73(33.9 \%)$ \\
\hline $\mathrm{C}$ & $75(34.9 \%)$ \\
\hline $\mathrm{D}$ & $38(17.7 \%)$ \\
\hline $\mathrm{E}$ & $17(7.9 \%)$ \\
\hline \multicolumn{2}{|l|}{ Location of the tumour (quadrant) } \\
\hline Upper-outer & $153(71.2 \%)$ \\
\hline Border of the lateral quadrants & $33(15.3 \%)$ \\
\hline Border of the upper quadrants & $29(13.5 \%)$ \\
\hline \multicolumn{2}{|l|}{ cT category } \\
\hline is & $25(11.6 \%)$ \\
\hline 1a & $20(9.3 \%)$ \\
\hline $1 b$ & $21(9.8 \%)$ \\
\hline $1 \mathrm{c}$ & $45(20.9 \%)$ \\
\hline 2 & $95(44.2 \%)$ \\
\hline 3 & $9(4.2 \%)$ \\
\hline \multicolumn{2}{|l|}{ cN category } \\
\hline 0 & $184(85.6 \%)$ \\
\hline 1 & $31(14.4 \%)$ \\
\hline Distant metastasis (at the end of the follow-up period), n (\%) & $3(1.4 \%)$ \\
\hline Operation time (median; min-max) minute & $47(35-85)$ \\
\hline Volume of the specimen $\left(\right.$ mean \pm SD) $\mathrm{cm}^{3}$ & $64.3 \pm 58.8$ \\
\hline Weight of the specimen (mean; min-max) gramm & $49.8(13.4-149.9)$ \\
\hline Pathological tumour size (invasive cancer) (mean \pm SD) $\mathrm{mm}$ & $30 \pm 13$ \\
\hline Pathological tumour size (DCIS) $($ mean \pm SD) $\mathrm{mm}$ & $23 \pm 7$ \\
\hline Pathological tumour size (invasive cancer + DCIS) $($ mean \pm SD) $\mathrm{mm}$ & $33 \pm 14$ \\
\hline \multicolumn{2}{|l|}{ pT category } \\
\hline is & $25(11.6 \%)$ \\
\hline $1 \mathrm{a}$ & $12(5.9 \%)$ \\
\hline $1 b$ & $21(9.8 \%)$ \\
\hline $1 \mathrm{c}$ & $36(16.7 \%)$ \\
\hline 2 & $82(38.1 \%)$ \\
\hline 3 & $10(5.6 \%)$ \\
\hline pN category & \\
\hline
\end{tabular}




\begin{tabular}{|c|c|}
\hline $\begin{array}{l}0 \\
1 \\
2 \\
3\end{array}$ & $\begin{array}{c}151(70.2 \%) \\
32(14.9 \%) \\
3(1.4 \%) \\
0(0 \%)\end{array}$ \\
\hline \multicolumn{2}{|l|}{ ypT category } \\
\hline $\begin{array}{l}0 \\
1 \mathrm{a} \\
1 \mathrm{~b} \\
2 \\
3 \\
\end{array}$ & $\begin{array}{c}15(7.0 \%) \\
7(3.3 \%) \\
5(2.3 \%) \\
2(0.9 \%) \\
0(0 \%) \\
\end{array}$ \\
\hline \multicolumn{2}{|l|}{ ypN category } \\
\hline $\begin{array}{l}0 \\
1 \\
2 \\
3\end{array}$ & $\begin{array}{l}18(8.3 \%) \\
8(3.7 \%) \\
3(1.4 \%) \\
0(0 \%)\end{array}$ \\
\hline \multicolumn{2}{|l|}{ Histological type } \\
\hline $\begin{array}{l}\text { DCIS } \\
\text { Invasive carcinoma (NST) } \\
\text { Invasive lobular carcinoma (ILC) } \\
\text { Other }\end{array}$ & $\begin{array}{c}25(11.6 \%) \\
145(67.4 \%) \\
41(19.1 \%) \\
4(1.9 \%) \\
\end{array}$ \\
\hline \multicolumn{2}{|l|}{ DCIS component } \\
\hline $\begin{array}{l}\text { yes } \\
\text { no } \\
\end{array}$ & $\begin{array}{l}115(53.5 \%) \\
100(46.5 \%)\end{array}$ \\
\hline \multicolumn{2}{|l|}{ Grade } \\
\hline $\begin{array}{l}1 \\
2 \\
3\end{array}$ & $\begin{array}{l}52(24.2 \%) \\
116(53.9 \%) \\
47(21.9 \%)\end{array}$ \\
\hline \multicolumn{2}{|l|}{ DCIS grade } \\
\hline $\begin{array}{l}1 \\
2 \\
3 \\
\text { Non-DCIS } \\
\end{array}$ & $\begin{array}{c}32(14.9 \%) \\
45(20.9 \%) \\
38(17.7 \%) \\
100(46.5 \%)\end{array}$ \\
\hline \multicolumn{2}{|l|}{ Molecular subtype } \\
\hline $\begin{array}{l}\text { Luminal-A like } \\
\text { Luminal-B like } \\
\text { HER-2 positive } \\
\text { Triple negative }\end{array}$ & $\begin{array}{c}157(73.0 \%) \\
25(11.6 \%) \\
18(8.4 \%) \\
15(7.0 \%)\end{array}$ \\
\hline Ki-67 (\%) & $25 \%(1-80 \%)$ \\
\hline \multicolumn{2}{|l|}{ Adjuvant RT } \\
\hline $\begin{array}{l}\text { Yes } \\
\text { No }\end{array}$ & $\begin{array}{c}211(98.1 \%) \\
4(1.9 \%)\end{array}$ \\
\hline \multicolumn{2}{|l|}{ Adjuvant endocrine therapy } \\
\hline $\begin{array}{l}\text { Yes } \\
\text { No }\end{array}$ & $\begin{array}{l}182(84.7 \%) \\
33(15.3 \%)\end{array}$ \\
\hline Follow-up (median; min-max) months & $47(7-85)$ \\
\hline
\end{tabular}

ALND: axillary lymph node dissection, DCIS: ductal carcinoma in situ, c: clinical, $p$ : pathological, RT: radiotherapy, SLNB: sentinel lymph node biopsy, y: following primer systemic therapy 


\subsubsection{Clinico-oncological results}

Positive surgical margins lead to re-excision in 13 cases $(6 \%)$, and mastectomy in 3 cases $(1.4 \%)$. Total recurrence rate was $4.7 \%(n=10)$ including 4 cases $(1.9 \%)$ of $L R, 3$ cases (1.4\%) of LRR and 3 cases $(1.4 \%)$ of distant metastases during the assessed time period. One patient died of distant metastases $(0.4 \%)$.

\subsubsection{Aesthetic and quality of life outcomes}

Subjective aesthetic outcome reached 4.2 points on the Likert scale (range: 2-5). Breast surgeons mostly agreed uniformly with the excellent aesthetic result. Based on BCCT.core software, the mean value of objective aesthetic outcome was 1.3 points (range: 14 points). According to BREAST-Q questionnaire the mean result of "satisfaction with the appearance of the breast", "discomfort caused by RT", "psychosocial well-being”, "physical well-being" and "sexual well-being" were rated 90, 78, 87, 78 and 60 points, respectively.

\section{Table 9.}

Table 9. Results of the BCCT.core and the BREAST-Q validated quality of life questionnaire

\begin{tabular}{|l|c|}
\hline BCCT.core (preoperative) & \\
\hline excellent & $175(81.4 \%)$ \\
good & $25(11.6 \%)$ \\
fair & $15(7.0 \%)$ \\
poor & $0(0 \%)$ \\
\hline BCCT.core (postoperative) & $163(75.9 \%)$ \\
excellent & $36(16.7 \%)$ \\
good & $16(7.4 \%)$ \\
fair & $0(0 \%)$ \\
poor & $90(59-100)$ \\
\hline BREAST-Q postop. 1 (median; min-max) & $78(21-100)$ \\
\hline BREAST-Q postop. 2 (median; min-max) & $87(14-100)$ \\
\hline BREAST-Q postop. 3 (median; min-max) & $78(21-100)$ \\
\hline BREAST-Q postop. 4 (median; min-max) & $60(0-100)$ \\
\hline BREAST-Q postop. 5 (median; min-max) & \\
\hline BCCT.core: Breast Cancer Conservative Treatment software, & $B R E A S T-Q, p o s t o p$. \\
\hline
\end{tabular}

satisfaction with the appearance of the breast, BREAST-Q postop. 2: discomfort caused by RT, BREAST-Q postop. 3: psychosocial well-being, BREAST-Q postop. 4: physical wellbeing, BREAST-Q postop. 5: sexual well-being 


\subsubsection{Complications and initiation time of adjuvant therapy}

Total complication rate was $11.2 \%(\mathrm{n}=24)$. Grade I complications were detected in 12 cases $(5.6 \%)$ (lymphoedema 7 (3.3\%), seroma $3(1.4 \%)$, suffusion $1(0.4 \%)$, impaired wound healing $1(0.4 \%)$ ), Grade II complications were detected in 7 cases $(3.3 \%)$ (chronic seroma 3 (1.4\%), impaired wound healing $2(0.9 \%)$, inflammation $2(0.9 \%)$ ), and Grade III complications were detected in 5 cases (2.3\%) (haematoma evacuation 3 (1.4\%), inflammation $2(0.9 \%))$. Grade IV and Grade V complications were not observed. Median time interval between surgery and initiation of adjuvant therapy was 5 weeks (minimum 4 , maximum 12 weeks).

\subsubsection{Operation time}

Total surgery time was 47 minutes (35-85 minutes) including axillary surgery. 


\section{DISCUSSION}

5.1 Comparing the clinicopathological, cosmetic and quality of life outcomes of oncoplastic breast conserving surgery to conventional one. - based on the results of study 4.1

The first OBCS techniques were described more than two decades ago. Since then, the emphasis on the aesthetic outcomes and quality of life after breast cancer surgery has resulted in the development of various OBCS techniques. [24] However high level evidence to support the oncological safety and improved aesthetic outcome of OBCS are still lacking, thus there is little standardization of OBCS, which makes the scientific comparison of the techniques among each other and to CBCS challenging. [26]

In this retrospective analysis, the results of the therapeutic mammaplasty, the periareolar and the dermoglandular rotation OBCS procedures were compared to the outcomes of CBCS according to the following five clinico-oncological parameters.

\subsubsection{Oncological safety}

In this study, significant differences were not observed in the rates of LR and LRR between the OBCS and CBCS groups, which had total recurrence rates of $2.0 \%$ and $3.71 \%$, respectively. Recent studies with follow-up intervals of 3, 3-5 and 5 years had mean LRs of $1.7,3.7$, and $6.0 \%$ and distant metastases rates of $3.8,7.1$, and $11.9 \%$, respectively. [31]

The main advantage of OBCS techniques seems to be the ability to perform wider excisions without compromising the aesthetic outcomes, while reducing the risk of positive margins. [53] Our results revealed that the excised weight of the specimens was significantly larger in the OBCS group than in the CBCS group (90 g vs. $63 \mathrm{~g}$ ), even though there was no significant difference in pathological grade in the two groups. The explanation for the larger excised specimens in the OBCS group could be the significantly higher number of patients who underwent neoadjuvant chemotherapy with unfavourable biological tumour subtypes and larger initial clinical tumour sizes. Thus, the extended radicality of OBCS may result in the overtreatment of some breast cancer patients; however, in our study, significantly wider microscopically tumour-free margins ( $8 \mathrm{~mm}$ vs. $4.5 \mathrm{~mm}$ ) and a lower rate of completion surgeries due to positive surgical margins were found in the OBCS group compared to the CBCS group ( $\mathrm{n}=28(8.0 \%))$ vs. $\mathrm{n}=58(16.6 \%))$.

The appropriate indication for OBCS and the ideal specimen volume that should be resected according to the clinical tumour size were determined in a recent publication by 
Pukancsik et al. When the predicted resected volume is more than $10 \%$ of the entire breast volume of the inner quadrants and more than $15-19 \%$ of the volume of the outer quadrants, CBCS may not result in an acceptable aesthetic outcome. In cases involving a predictably larger volume loss than discussed above, OBCS might be a better treatment choice than CBCS. [14]

A recent publication by Carter et al. showed a lower rate $(5.8 \%)$ of positive or close margins after OBCS than after CBCS (8.3\%). Down et al. found a significantly lower need for re-excision after OBCS (37 patients) than after CBCS (121 patients) (5.4\% vs. 28.9\%). [54] [30]

Among studies that reported oncologic outcome data for OBCS procedures, the crude OS and DFS rates were 95.0 and $90.0 \%$. [31] In line with the international results, our findings (Figure 5.a-b) showed an OS rate of $100.0 \%$ and a DFS rate of $88.5 \%$ for patients who underwent OPS, while in patients who underwent classic BCS, the OS and the DFS rates were found to be $97.3 \%$ and $78.2 \%$, respectively. The groups did not differ in terms of the observed survival rates.

Figure 5.a-b Disease free and overall survival rate of oncoplastic and the conventional breastconserving surgery groups

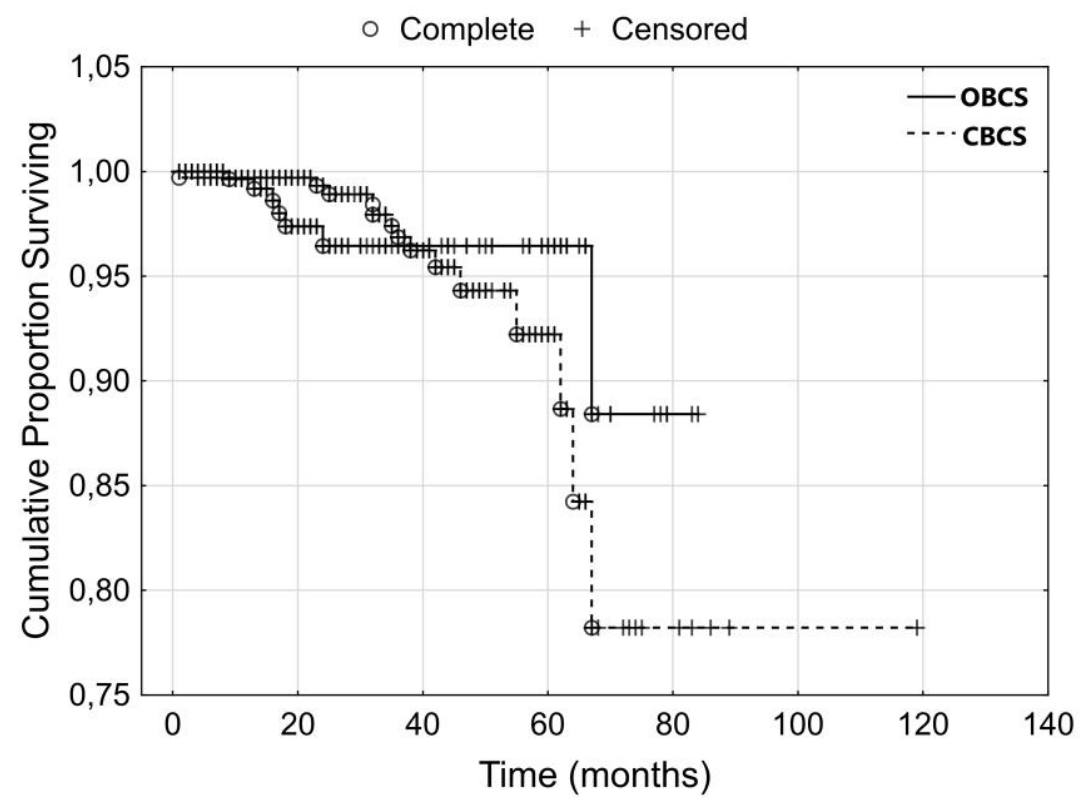

Figure 5.a Disease free survival rate of the OBCS and the CBCS group 


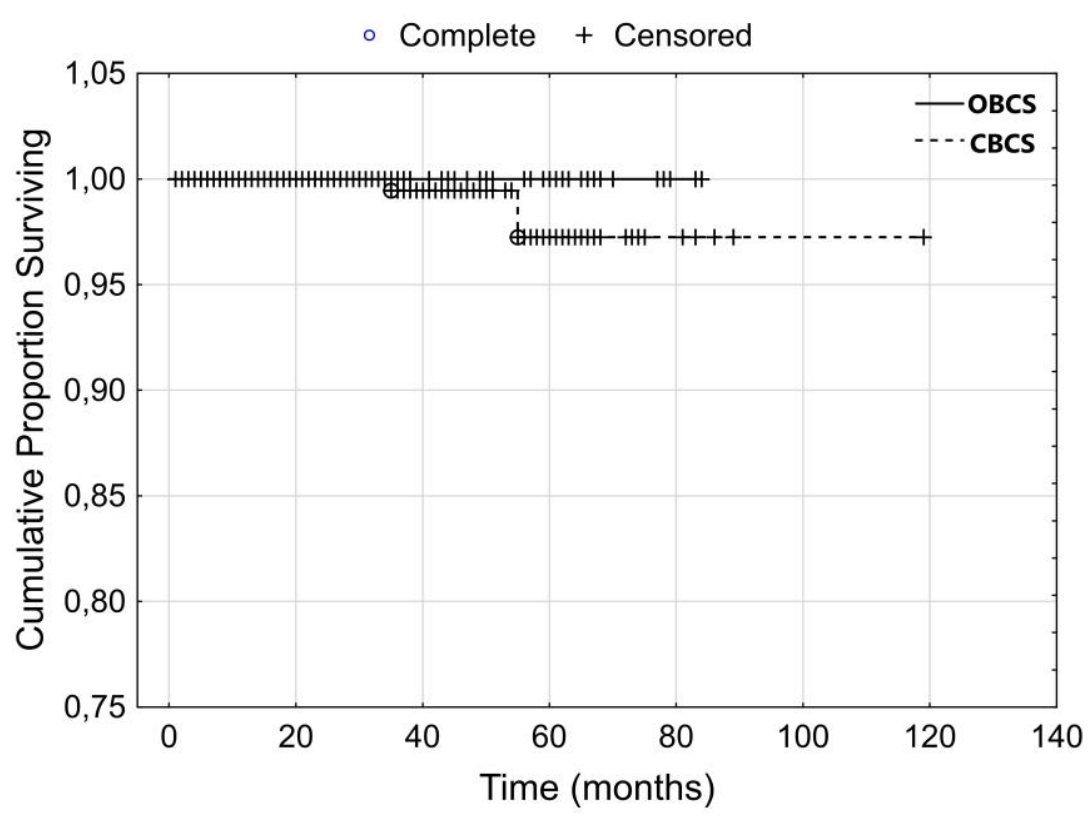

Figure 5.b Overall survival rate of the OBCS and the CBCS group

\subsubsection{Frequency of complications}

According to our data, OBCS does not seem to increase morbidity compared to CBCS; moreover, the rate of complications was slightly higher in the CBCS group (6.5\%) with the most common complication of seroma formation, found in $2.6 \%$ of the cases.

In the OBCS group, complications occurred in $5.7 \%$ of the cases, and the most common complication was infection, which occurred in a total of $2.3 \%$ of the cases. The rates of revisional surgery were similar in the investigated groups.

A recent large systematic review by De La Cruz et al. involving 6011 breast cancer patients demonstrated no statistically significant difference in the incidence of postoperative complications among women undergoing oncoplastic and non-oncoplastic lumpectomies. [31] However, Tenofsky et al. [55] found a higher incidence of non-healing wounds in the oncoplastic group than in the non-oncoplastic group (8.6\% vs. $1.2 \%)$, although this higher incidence did not prolong the time to radiation for the oncoplastic group. Therefore, oncoplastic reconstruction at the time of BCS does not appear to significantly increase the risk of postoperative complications that would delay initiation of adjuvant therapy. [31] 


\subsubsection{Initiation time of adjuvant therapy}

The median time to the initiation of adjuvant treatment was almost the same in the OBCS and CBCS groups (4.2 weeks vs. 4.1 weeks). In the OBCS group, our results were in line with those of the majority of the current publications, showing no delay in the time to the initiation of adjuvant treatments due to complications. [56,57]

\subsubsection{Aesthetic outcome and quality of life}

A meta-analysis of 61 publications comparing 3165 patients after OBCS with 5494 patients after CBCS showed that satisfaction with the aesthetic outcome was higher in the OBCS group than in the CBCS group (89.5\% vs. $82.9 \%, \mathrm{p}<0.001)$. [58]

In a prospective study, Veiga et al. demonstrated significantly higher quality of life outcomes in the OBCS group than in the CBCS group. [59]

At the $1^{\text {st }}$ postoperative year, the results of the EORTC questionnaire rated by the patients showed that all median values for the quality of life outcomes (emotional functioning, social functioning, body image) were greater than 83.4 points, representing a high quality of life in the OBCS group that was significantly better than that of the CBCS group. In the CBCS group, the vast majority of the patients rated their quality of life parameters near 71.2.

According to our data, patients who underwent OBCS had higher median aesthetic outcome scores than the patients treated with CBCS (4.4 vs. 3.2 points).

\subsubsection{Operation time}

According to a recent publication, patients who underwent wide local excision required significantly shorter operation times than those patients who underwent OBCS (62 minutes vs. 91.4 minutes). [11-13]

In a prospective cohort study by Clough et al., out of 101 OBCS cases, 89 patients underwent immediate contralateral symmetrisation, with a mean operation time of 2 hours. [60]

In the present study, even without immediate contralateral symmetrisation, the OBCS cases required significantly (10 minutes) longer operative times than the CBCS cases. 


\subsection{Assessing the clinipathological, cosmetic and quality of life outcomes of the central pedicled, modified Wise-pattern oncoplastic technique - based on the results of study 4.2}

TM in ptotic or moderate- or large-breasted patients is a versatile technique allowing the removal of tumours in almost every quadrant of the breast with improved cosmetic results and similar five-year survival and local recurrence rates to those of conventional breastconserving surgery. $[56,60,61]$

Few studies have investigated the role of the central pedicled, Wise-pattern technique in OBCS. The present study aimed to facilitate the repeatability, utility of the modified Wisepattern technique in volume-displacement OBCS, thus becoming a standard oncoplastic technique and gaining wider acceptance.

\subsubsection{Oncological safety}

In this study, with a mean follow-up of 43.9 months, the overall recurrence rate was found to be $5.8 \%$, which does not differ significantly from those of the classic TM techniques. Kronowitz et al. reported a 5\% LR rate after a mean follow-up of 36 months [62], while a slightly lower rate (2\%) was found by Losken after a mean follow-up of 40 months using the classic, dermal pedicled TM techniques. [63]

\subsubsection{Surgical margins}

The ability to perform a large partial mastectomy thanks to TM oncoplastic techniques in reconstructing the breast allows for lower positive margin rates reported to be in $10 \%$ to $12 \%$ range in several large review studies. [64] Our data showed that the mean free surgical margin was $7 \mathrm{~mm}$, which could explain the low re-excision $(5.8 \%)$ and mastectomy rates $(1.1 \%)$ due to positive or close surgical margins.

\subsubsection{Frequency of complications and the initial time of adjuvant therapy}

In a recent published meta-analysis, the average complication rate in the oncoplastic reduction mammaplasty group was $16 \%$ and do not cause a significant delay in the initiation of adjuvant treatments. [65-68]

In accordance with the data of current studies, the median time to the initiation of adjuvant treatments was 4.9 months. Therefore, a delay in adjuvant treatments was not verified. 
The overall complication rate was $12.9 \%$. A majority of the complications were classified as minor and healed spontaneously using conservative treatments. The most common complication was skin redness, a clinical sign of lymphoedema, with a rate of $3.1 \%$. The second most common complication was wound dehiscence, with a rate of $2.9 \%$. The rates of fat necrosis and partial or total NAC necrosis were both under $2 \%$, highlighting the vascular reliability of the central pedicled modified Wise-pattern OBCS. Furthermore, the rate of seroma formation was only $0.9 \%$, which can be explained by the accurate closure of the defects with the extended mobilization provided by the modified Wise-pattern TM.

According to our findings and the multivariate analysis, there were no significant correlations between active smoking, BMI, diabetic co-morbidity and the observed complications.

\subsubsection{Aesthetic outcome}

The satisfaction and aesthetic outcomes are reportedly very high in patients treated with TM. [69] In the publication of Chang et al., 70\% of the patients who underwent TM rated the final cosmetic result as excellent. [70]

Our data demonstrate that the majority of the breast surgeons agreed with the statement "This case has an excellent aesthetic outcome", with a mean score of 4.1. In addition, the median overall objective outcome score was 1.9. Both the subjective and objective aesthetic results represented an improved cosmetic outcome when the modified Wise-pattern OBCS was applied.

\subsubsection{Length of operation}

The only drawback of the TM seems to be the longer operative time, in which concomitant contralateral symmetrization could be an important factor. [28]

Nos et al. reported the mean operative time as 150 minutes, including ALND and symmetrization of the contralateral breast. [71]

Here, the mean time in bilateral cases was 119 minutes with SLNB or ALND. The cases without contralateral symmetrization required a mean time of 69 minutes with SLNB or ALND. 


\subsection{Assessing the clinipathological, cosmetic and quality of life outcomes of the modified Regnault " $B$ " oncoplastic technique - based on the results of study 4.3}

No paper has been published on BCS as modified volume-displacement level II oncoplastic OBCS technique described by Regnault P in 1974, and presented by the authors. [72] Existing publications only refer to breast reduction. [73,74] In this paper the authors present the detailed surgery description of modified Regnault "B" level II OBCS technique and associated clinicopathological assessment for the first time. Data were compared to the outcome of other level II OBCS techniques.

The Regnault "B" OBCS technique can be applied safely for BCS of medium-sized or large breasts with minimum $20 \%$ and maximum $50 \%$ volume loss. In addition to an excellent aesthetic outcome, the presented technique does not increase LR rate compared to traditional breast-conserving surgeries. [56,60,61] According to our study, tumour recurrence was observed in $4.7 \%$ of all cases during follow-up period of 47 months, which does not differ from 5\% recurrence rate during 36 follow-up period presented by Kronowitz et al. [62] Losken found in his study that over a mean follow-up period of 40 months local recurrence rate was $2 \%$ for level II oncoplastic techniques corresponding to $1.9 \%$ described in our study. [63]

OBCS techniques have the advantage of less positive surgical margins [7,23]. Based on the study published by McIntosh et al, the rate of completion surgeries was $7.2 \%$ which also corresponds to the outcomes of our study showing a rate of 7.4\%. [65] In our study the rate of completion re-excision/mastectomy (6\% vs $1.4 \%$ ) was higher than in the study of McIntosh (3.5\% vs 3.7\%).

Based on literature data, the frequency of complications with therapeutic breast reconstruction may be $0 \%$ to $36 \%$ which will not delay significantly the start of adjuvant therapy. [65-68] According to our study, the median interval between surgery and initiation of adjuvant treatment was 5 weeks corresponding to published international outcomes.

Total complication rate was $11.2 \%$ based on study data. Grade I complications were the most frequent and healed spontaneously in most cases. The most common complication was lymphoedema with erythema of the breast (3.3\%). Chronic seroma occurred in only 3 cases $(1.3 \%)$. ALND surgery was performed in all three cases where multiple puncture of the axilla was required after drain removal. Grade I seroma also developed in only 3 cases $(1.3 \%)$ which can be explained by the fact that the wound cavity, which is formed following radical tumour removal, is filled by mobilising and displacing surrounding glandular pillars, and 
avoiding an "open" wound cavity. Based on multivariable analysis, no significant association was found between diabetes, smoking habits or BMI, and complications.

Surveys regarding therapeutic breast reconstruction surgery report high level of patient satisfaction [69]. Chang et al. reported in their study "excellent" aesthetic outcome after therapeutic breast reconstruction in $70 \%$ of cases. [70] According to our results, a mean value of 4.1 points on the subjective aesthetic Likert scale corresponds to the statement that "the Regnault B OBCS technique provides excellent aesthetic outcome", which is confirmed by an average objective value of 1.3 on BCCT.core which also corresponds to an "excellent" rating. As it does not require any symmetrisation, the average surgery time was 47 minutes which does not increase surgery time significantly compared to traditional breast-conserving surgeries. [28] Furthermore, it provided targeted re-excision in addition to excellent aesthetic outcome. In our study, completing re-excision/mastectomy rate (6\% vs 1.4\%) was higher than in the study by McIntosh (3.5\% vs 3.7\%). [65] The surgical technique has the disadvantage that in case of a completion mastectomy incisions on the skin envelope make an immediate reconstruction difficult. 


\section{CONCLUSIONS}

In general it can be stated that high level evidence to support the oncological safety and improved aesthetic outcome of OBCS are still lacking, thus currently there is still some standardization of OBCS. It is essential to provide more long-term studies regarding the reproducibility, utility, low interference of OBCS techniques with the oncologic treatment and higher satisfaction of breast cancer patients facilitating the standardization of the oncoplastic techniques.

6.1 Our results revealed that the investigated volume displacement OBCS techniques (therapeutic mammaplasty, dermoglandular rotation and periareolar) in line with the CBCS technique:

a. are able to provide the oncological safety with low morbidity b. can provide the local tumour control with radical tumour resection, reducing the rate of re-excision and completion mastectomies

c. do not cause delay in initiation of the adjuvant therapies

6.2 Our results revealed that the OBCS techniques allow the removal of large volumes of breast tissue with improved cosmetic and quality of life outcomes providing higher satisfaction of the breast cancer patients compared to CBCS cases.

Additionally it should be stated that, the aforementioned OBCS techniques required longer operation times than the CBCS. Furthermore, the extended radicality of OBCS could reduce the rate of re-excision and completion mastectomies, although it may result in overtreatment of some breast cancer patients, highlighting the importance of appropriate patient selection for OBCS.

6.3 Our results revealed that the "modified" Wise-pattern OBCS technique out team first presented in the international literature:

a. is a safe and reproducible volume-displacement OBCS in ptotic and moderate- or large-breasted patients with a low complication rate

b. is able to minimize the rate of positive surgical margins, providing radical level II resections, thus the adequate local tumour control 
c. can provide the immediate symmetry and improve the aesthetic and quality of life outcomes contributing to the satisfaction of breast cancer patients

The "modified" Wise-pattern OBCS could be a standard level II oncoplastic technique of T1-T3 tumours allowing real anatomic uni- or even bi-quadrantectomy resections from the periphery of the parenchyma up to the retromammary space in a "slice of cake" manner for solitary or multicentric tumours in any quadrant (even the central) of the breast.

Additionally, it should be noted that the "modified" Wise-pattern technique requires the symmetrisation of contralateral breast resulting in longer operation time.

6.4 Our results revealed that the "modified" Regnault B OBCS technique which technique out team was the firs present in the international literature:

a. is a safe and repeatable volume-displacement OBCS technique in ptotic and medium- or large-breasted patients with low complication rate

b. is suitable for removing $20 \%$ to $50 \%$ of breast parenchyma providing adequate surgical margins thus maintaining the local tumour control

c. able to provide high level of patient satisfaction and cosmetic outcomes with improved quality of life

The "modified" Regnault B OBCS could be a standard level II oncoplastic technique of T1-T3 tumours located in the upper-outer quadrant as the most common location of breast cancer.

The "modified" Regnault B OBCS technique has the advantage that it does not require contralateral symmetrisation surgery, while its disadvantage is that in case of completion mastectomy, incisions made on the skin envelope of the breast make immediate reconstruction difficult but do not exclude it. 


\section{ACKNOWLEDGEMENTS}

I would like to express my special appreciation and thanks to:

- habil Dr. Zoltán Mátrai for his time, continuous support, scientific guidance and professional supervision of my thesis

- Dr. Dávid Pukancsik for his continuous support as core member of the oncoplastic clinical scientific team and editing some of the related articles

- Prof. Dr. Csaba Polgár the head of the Institute and the former director Prof. Dr. Miklós Kásler the Minister of Human Capacities for providing me with the professional environment and facilities of the National Institute of Oncology to complete the thesis

- Prof. Dr. Mihály Bak for the scientific and practical guidance in the doctorial school

- all my colleagues of the National Institute of Oncology, especially in the Breast and Sarcoma Surgery Department for assisting in my daily practice and in data collection

- Radiological Diagnostics for providing data for the studies

- the Department of Surgical and Molecular Pathology for providing data used in this study

- Dr. István Kenessey for his professional assistance with the statistical analysis

- my parents, wife, childrens, friends and former teachers for their understanding, encouraging and supporting during the completion of this work 


\section{REFERENCES}

1. Kasler M, Otto S and Kenessey I. The current situation of cancer morbidity and mortality in the light of the National Cancer Registry. Orv Hetil 2017;158:84-9.

2. Ujhelyi M, Pukancsik D, Kelemen P, et al. Breast cancer care quality analysis of the National Institute of Oncology in Hungary according to the requirements of European Society of Breast Cancer Specialists (EUSOMA). Orv Hetil 2016;157:1674-82.

3. Hungarian National Cancer Registry: http://www.onkol.hu/hu/rakregiszter-statisztika

4. Ujhelyi M, Pukancsik D, Kelemen P, et al. Barriers to Organized Mammography Screening Programs in Hungary: A Questionnaire-based Study of 3,313 Women. Anticancer Res 2018;38:1727-34.

5. Fisher B, Anderson S, Bryant J, et al. Twenty-year follow-up of a randomized trial comparing total mastectomy, lumpectomy, and lumpectomy plus irradiation for the treatment of invasive breast cancer. N Engl J Med 2002;347:1233-41.

6. Veronesi U, Cascinelli N, Mariani L, et al. Twenty-year follow-up of a randomized study comparing breast-conserving surgery with radical mastectomy for early breast cancer. $\mathrm{N}$ Engl J Med 2002;347:1227-32.

7. Matrai Z, Gulyas G, Kovacs E, et al. Oncoplastic versus conventional breast conserving surgery. A comparison of clinicopathological findings, cosmetic results and quality of life in 60 cases. Magy Onkol 2014;58:116-27.

8. Kahan Z. Medical treatment options in BRCA-associated cancers. Magy Onkol 2020;64:13-24.

9. Maraz R, Venczel L, Sikorszki L, et al. The importance of the extracapsular extension of the sentinel node metastasis in the surgical treatment of breast cancer. Magy Seb 2020;73:16-22.

10. Singletary SE. Surgical margins in patients with early-stage breast cancer treated with breast conservation therapy. Am J Surg 2002;184:383-93.

11. Cochrane RA, Valasiadou P, Wilson AR, et al. Cosmesis and satisfaction after breastconserving surgery correlates with the percentage of breast volume excised. Br J Surg 2003;90:1505-9. 
12. Matrai Z, Gulyas G, Toth L, et al. Challenges in oncologic plastic surgery of the breast. Magy Onkol 2011;55:40-52.

13. Szollar A, Ujhelyi M, Polgar C, et al. A long-term retrospective comparative study of the oncological outcomes of 598 very young ( $</=35$ years) and young (36-45 years) breast cancer patients. Eur J Surg Oncol 2019;45:2009-15.

14. Pukancsik D, Kelemen P, Ujhelyi M, et al. Objective decision making between conventional and oncoplastic breast-conserving surgery or mastectomy: An aesthetic and functional prospective cohort study. Eur J Surg Oncol 2017;43:303-10.

15. Hamdi M. Oncoplastic and reconstructive surgery of the breast. Breast 2013;22 Suppl 2:S100-5.

16. Matrai Z, Kenessey I, Savolt A, et al. Evaluation of patient knowledge, desire, and psychosocial background regarding postmastectomy breast reconstruction in Hungary: a questionnaire study of 500 cases. Med Sci Monit 2014;20:2633-42.

17. Audretsch W. Space-holding technic and immediate reconstruction of the female breast following subcutaneous and modified radical mastectomy. Arch Gynecol Obstet 1987;241 Suppl:S11-9.

18. Mátrai-Gulyás-Kásler. Az emlörák korszerű sebészete Medicina könyvkiadó 2015.

19. Zucca-Matthes G, Manconi A, da Costa Viera RA, et al. The evolution of mastectomies in the oncoplastic breast surgery era. Gland Surg 2013;2:102-6.

20. Mansfield L, Agrawal A and Cutress RI. Oncoplastic breast conserving surgery. Gland Surg 2013;2:158-62.

21. Lazar G, Bursics A, Farsang Z, et al. Modern surgical treatment of breast cancer. 3rd Breast Cancer Consensus Conference. Magy Seb 2016;69:117-32.

22. Clough KB, Kaufman GJ, Nos C, et al. Improving breast cancer surgery: a classification and quadrant per quadrant atlas for oncoplastic surgery. Ann Surg Oncol 2010;17:1375-91.

23. Kelemen P, Pukancsik D, Ujhelyi M, et al. Comparison of clinicopathologic, cosmetic and quality of life outcomes in 700 oncoplastic and conventional breast-conserving surgery cases: A single-centre retrospective study. Eur J Surg Oncol 2019;45:118-24.

24. Fitoussi A, Berry, M.G., Couturaud, B., Salmon, R.J. . Oncoplastic and Reconstructive Surgery for Breast Cancer, The Institut Curie Experience. Springer-Verlag Berlin Heidelberg 2009.

25. Mátrai Z, Gulyas G, Kovacs T, et al. Principles and Practice of Oncoplastic Breast Surgery. 2019. 
26. Weber WP, Soysal SD, El-Tamer M, et al. First international consensus conference on standardization of oncoplastic breast conserving surgery. Breast Cancer Res Treat 2017;165:139-49.

27. Matrai Z, Ujhelyi M, Kovacs T, et al. Evaluation of a Retroglandular Oncoplastic Technique as a Standard Level I Oncoplastic Breast-Conserving Surgery: A Retrospective Clinicopathologic Study of 102 Patients With Breast Cancer. Clin Breast Cancer 2019;19:e459-e67.

28. Haloua MH, Krekel NM, Winters HA, et al. A systematic review of oncoplastic breast-conserving surgery: current weaknesses and future prospects. Ann Surg 2013;257:60920.

29. Panhofer P, Ferenc V, Schutz M, et al. Standardization of morbidity assessment in breast cancer surgery using the Clavien Dindo Classification. Int J Surg 2014;12:334-9. 30. Carter SA, Lyons GR, Kuerer HM, et al. Operative and Oncologic Outcomes in 9861 Patients with Operable Breast Cancer: Single-Institution Analysis of Breast Conservation with Oncoplastic Reconstruction. Ann Surg Oncol 2016;23:3190-8.

31. De La Cruz L, Blankenship SA, Chatterjee A, et al. Outcomes After Oncoplastic Breast-Conserving Surgery in Breast Cancer Patients: A Systematic Literature Review. Ann Surg Oncol 2016;23:3247-58.

32. Senkus E, Kyriakides S, Ohno S, et al. Primary breast cancer: ESMO Clinical Practice Guidelines for diagnosis, treatment and follow-up. Ann Oncol 2015;26 Suppl 5:v8-30.

33. Giuliano AE, Ballman KV, McCall L, et al. Effect of Axillary Dissection vs No Axillary Dissection on 10-Year Overall Survival Among Women With Invasive Breast Cancer and Sentinel Node Metastasis: The ACOSOG Z0011 (Alliance) Randomized Clinical Trial. Jama 2017;318:918-26.

34. Savolt A, Peley G, Polgar C, et al. Eight-year follow up result of the OTOASOR trial: The Optimal Treatment Of the Axilla - Surgery Or Radiotherapy after positive sentinel lymph node biopsy in early-stage breast cancer: A randomized, single centre, phase III, noninferiority trial. Eur J Surg Oncol 2017;43:672-9.

35. Sinn HP, Helmchen B and Wittekind $\mathrm{CH}$. TNM classification of breast cancer: changes and comments on the 7th edition. Pathologe 2010;31:361-6.

36. Fayers P and Bottomley A. Quality of life research within the EORTC-the EORTC QLQ-C30. European Organisation for Research and Treatment of Cancer. Eur J Cancer 2002;38 Suppl 4:S125-33. 
37. Giuliano AE, Kirgan DM, Guenther JM, et al. Lymphatic mapping and sentinel lymphadenectomy for breast cancer. Ann Surg 1994;220:391-8; discussion 8-401.

38. Cardoso JS and Cardoso MJ. Towards an intelligent medical system for the aesthetic evaluation of breast cancer conservative treatment. Artif Intell Med 2007;40:115-26.

39. Würinger E, Mader N, Posch E, et al. Nerve and vessel supplying ligamentous suspension of the mammary gland. Plastic Reconstr Surg 1998;101:1486-93.

40. Wuringer E. Secondary reduction mammaplasty. Plast Reconstr Surg 2002;109:812-4.

41. Senkus E, Kyriakides S, Penault-Llorca F, et al. Primary breast cancer: ESMO Clinical Practice Guidelines for diagnosis, treatment and follow-up. Ann Oncol 2013;24 Suppl 6:vi723.

42. Senkus E, Kyriakides S, Ohno S, et al. Primary breast cancer: ESMO Clinical Practice Guidelines for diagnosis, treatment and follow-up. Ann Oncol 2015;26 Suppl 5:v8-30.

43. Kasler M, Polgar C and Fodor J. Current status of treatment for early-stage invasive breast cancer. Orv Hetil 2009;150:1013-21.

44. Lazar G, Bursics A, Farsang Z, et al. 3rd Hungarian Breast Cancer Consensus Conference - Surgery Guidelines. Magy Onkol 2016;60:194-207.

45. Forrai G, Szabo E, Ormandi K, et al. Imaging methods in the current diagnosis of and screening for breast cancer. Magy Onkol 2010;54:211-6.

46. Horvath Z, Boer K, Dank M, et al. Systemic therapy of breast cancer: practice guideline. Magy Onkol 2016;60:241-57.

47. Giuliano AE, Hunt KK, Ballman KV, et al. Axillary dissection vs no axillary dissection in women with invasive breast cancer and sentinel node metastasis: a randomized clinical trial. JAMA 2011;305:569-75.

48. Cserni G, Francz M, Jaray B, et al. Pathologic diagnosis and histopathology record of breast cancer. Magy Onkol 2010;54:217-26.

49. Lang I, Kahan Z, Pinter T, et al. Pharmaceutical therapy of breast cancer. Magy Onkol 2010;54:237-54.

50. Dindo D, Demartines N and Clavien PA. Classification of surgical complications: a new proposal with evaluation in a cohort of 6336 patients and results of a survey. Ann Surg 2004;240:205-13.

51. Clavien PA, Barkun J, de Oliveira ML, et al. The Clavien-Dindo classification of surgical complications: five-year experience. Ann Surg 2009;250:187-96.

52. Pusic AL, Klassen AF, Scott AM, et al. Development of a new patient-reported outcome measure for breast surgery: the BREAST-Q. Plast Reconstr Surg 2009;124:345-53. 
53. Cali Cassi L, Vanni G, Petrella G, et al. Comparative study of oncoplastic versus nononcoplastic breast conserving surgery in a group of 211 breast cancer patients. Eur Rev Med Pharmacol Sci 2016;20:2950-4.

54. Down SK, Jha PK, Burger A, et al. Oncological advantages of oncoplastic breastconserving surgery in treatment of early breast cancer. Breast J 2013;19:56-63.

55. Tenofsky PL, Dowell P, Topalovski T, et al. Surgical, oncologic, and cosmetic differences between oncoplastic and nononcoplastic breast conserving surgery in breast cancer patients. Am J Surg 2014;207:398-402; discussion

56. Rietjens M, Urban CA, Rey PC, et al. Long-term oncological results of breast conservative treatment with oncoplastic surgery. Breast 2007;16:387-95.

57. Campbell EJ and Romics L. Oncological safety and cosmetic outcomes in oncoplastic breast conservation surgery, a review of the best level of evidence literature. Breast Cancer (Dove Med Press) 2017;9:521-30.

58. Losken A, Dugal CS, Styblo TM, et al. A meta-analysis comparing breast conservation therapy alone to the oncoplastic technique. Ann Plast Surg 2014;72:145-9. 59. Veiga D, Veiga-Filho J, M Ribeiro L, et al. Evaluations of aesthetic outcomes of oncoplastic surgery by surgeons of different gender and specialty: A prospective controlled study. 2011.

60. Clough KB, Lewis JS, Couturaud B, et al. Oncoplastic techniques allow extensive resections for breast-conserving therapy of breast carcinomas. Ann Surg 2003;237:26-34. 61. Chang EI, Peled AW, Foster RD, et al. Evaluating the feasibility of extended partial mastectomy and immediate reduction mammoplasty reconstruction as an alternative to mastectomy. Ann Surg 2012;255:1151-7.

62. Kronowitz SJ, Hunt KK, Kuerer HM, et al. Practical guidelines for repair of partial mastectomy defects using the breast reduction technique in patients undergoing breast conservation therapy. Plast Reconstr Surg 2007;120:1755-68.

63. Losken A, Styblo TM, Carlson GW, et al. Management algorithm and outcome evaluation of partial mastectomy defects treated using reduction or mastopexy techniques. Ann Plast Surg 2007;59:235-42.

64. Chatterjee A, Dayicioglu D, Khakpour N, et al. Oncoplastic Surgery: Keeping It Simple With 5 Essential Volume Displacement Techniques for Breast Conservation in a Patient With Moderate- to Large-Sized Breasts. Cancer Control 2017;24:1073274817729043. 65. McIntosh J and O'Donoghue JM. Therapeutic mammaplasty--a systematic review of the evidence. Eur J Surg Oncol 2012;38:196-202. 
66. Spear SL, Pelletiere CV, Wolfe AJ, et al. Experience with reduction mammaplasty combined with breast conservation therapy in the treatment of breast cancer. Plast Reconstr Surg 2003;111:1102-9.

67. Gulcelik MA, Dogan L, Camlibel M, et al. Early complications of a reduction mammoplasty technique in the treatment of macromastia with or without breast cancer. Clin Breast Cancer 2011;11:395-9.

68. Denewer A, Elnahas W, Hussein O, et al. Evaluation of inferior pedicle therapeutic mammoplasty as a primary procedure for upper quadrants early breast cancer. Adv Breast Cancer Res 2013;2:86-90.

69. Munhoz AM, Montag E and Gemperli R. Current aspects of therapeutic reduction mammaplasty for immediate early breast cancer management: an update. World J Clin Oncol 2014;5:1-18.

70. Chang E, Johnson N, Webber B, et al. Bilateral reduction mammoplasty in combination with lumpectomy for treatment of breast cancer in patients with macromastia. Am J Surg 2004;187:647-50; discussion 50-1.

71. Nos C, Fitoussi A, Bourgeois D, et al. Conservative treatment of lower pole breast cancers by bilateral mammoplasty and radiotherapy. Eur J Surg Oncol 1998;24:508-14. 72. Regnault P. Reduction mammaplasty by the "B" technique. Plast Reconstr Surg 1974;53:19-24.

73. Rong GH. Reduction mammoplasty using a modified "B" shape method. Zhonghua Zheng Xing Shao Shang Wai Ke Za Zhi 1990;6:10-1, 73.

74. Giovanoli P, Meuli-Simmen C, Meyer VE, et al. Which technique for which breast? A prospective study of different techniques of reduction mammaplasty. Br J Plast Surg 1999;52:52-9. 
9. APPENDIX 